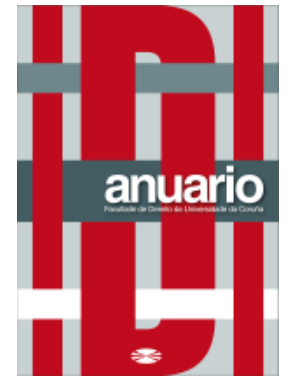

Anuario da Facultade de Dereito da Universidade da Coruña

Vol. 22 (2018), pp. 357-384

ISSNe: 2530-6324 || ISSN: 1138-039X

DOI: https://doi.org/10.17979/afdudc.2018.22.0.5191

\title{
NOMBRAMIENTOS DISCRECIONALES EN LA CARRERA JUDICIAL
}

\author{
RICARDO PEDRO RON LATAS \\ Profesor Titular de Universidad - Universidade da Coruña \\ Magistrado suplente TSJ/Galicia \\ JOSÉ FERNANDO LOUSADA AROCHENA \\ Magistrado especialista de lo social - TSJ/Galicia \\ Doctor en Derecho / Graduado Social
}

Resumen: La promoción profesional de Jueces y Magistrados dentro de la Carrera Judicial es una materia sensible desde la perspectiva de la independencia judicial, con una evidente vinculación con la exigencia de inamovilidad, y que se debe inspirar en criterios objetivos, evitando las arbitrariedades, preferencias o veleidades de los órganos gestores del estatuto judicial. Sin embargo, aunque la provisión de la mayoría de destinos de la Carrera Judicial se hace por concurso, existen otros muchos de especial importancia que resultan ser nombramientos discrecionales.

Palabras clave: independencia judicial, jueces y magistrados, Consejo General del Poder Judicial, Poder Judicial, nombramientos discrecionales.

Abstract: The professional promotion of Judges and Magistrates within the Judicial Career is a sensitive matter from the perspective of judicial independence, with an evident link with the requirement of immobility, and that should be inspired by objective criteria, avoiding arbitrariness, preferences or vagueness of the bodies managing the judicial status. However, although the provision of most of the Judicial Career's fates is made through a contest, there are many others of special importance that turn out to be discretionary appointments. 
Keywords: judicial independence, judges and magistrates, General Council of the Judiciary, judicial system, discretionary appointments.

SUMARIO: I. NOMBRAMIENTOS REGLADOS Y NOMBRAMIENTOS DISCRECIONALES EN LA CARRERA JUDICIAL EN LA LEY ORGÁNICA DEL PODER JUDICIAL. II. UN INICIAL DESARROLLO REGLAMENTARIO REFORZADO CON UN CONTROL JUDICIAL LIMITADO A VERIFICAR LAS CONDICIONES OBJETIVAS PERO SIN ENJUICIAR LA DISCRECIONALIDAD TÉCNICA. III. DE UN CONTROL JUDICIAL LIMITADO A VERIFICAR LAS CONDICIONES OBJETIVAS A UN CONTROL JUDICIAL CON ENJUICIAMIENTO DE LA DISCRECIONALIDAD TÉCNICA. IV. EL REGLAMENTO DEL CONSEJO GENERAL DEL PODER JUDICIAL 1/2010, DE 25 DE FEBRERO, SOBRE PROVISIÓN DE PLAZAS DE NOMBRAMIENTO DISCRECIONAL DE LOS ÓRGANOS JUDICIALES. V. ACCESO DE LAS JUEZAS A LAS ALTAS INSTANCIAS JUDICIALES Y NOMBRAMIENTOS DISCRECIONALES: LAS SOLUCIONES APUNTADAS EN EL PLAN DE IGUALDAD DE LA CARRERA JUDICIAL. VI. ULTIMAS TENDENCIAS MARCADAS EN LAS SENTENCIAS DEL TRIBUNAL SUPREMO SOBRE NOMBRAMIENTOS DISCRECIONALES DENTRO DE LA CARRERA JUDICIAL.

\section{NOMBRAMIENTOS REGLADOS Y NOMBRAMIENTOS DISCRECIONALES EN LA CARRERA JUDICIAL EN LA LEY ORGÁNICA DEL PODER JUDICIAL.}

La promoción profesional de jueces y magistrados dentro de la carrera judicial es una materia sensible desde la perspectiva de la independencia judicial, con una evidente vinculación con la exigencia inamovilidad ${ }^{1}$, y que se debe inspirar en criterios objetivos, evitando arbitrariedades, preferencias o veleidades de los órganos gestores del estatuto judicial - históricamente el Ministerio de Justicia ${ }^{2}$, y desde la Constitución Española de 1978, el CGPJ ${ }^{3}$ - , de ahí que el artículo 326, apartado 1, de la Ley Orgánica 6/1985, de 1 de julio, del Poder Judicial (en adelante, la LOPJ), establezca, con carácter general, que el ascenso y promoción profesional de los jueces y magistrados dentro de la carrera judicial "estará basado en los principios de mérito y capacidad, así como en la idoneidad y especialización para el ejercicio de las funciones jurisdiccionales correspondientes a los diferentes destinos". Añade en su apartado 2 que "la provisión de destinos de la Carrera Judicial se hará por concurso, en la forma que determina esta Ley”, esto es, por criterios objetivos — por regla general, el mejor puesto escalafonal conjugado con especialización y antigüedad en el orden jurisdiccional-, lo que garantiza la objetividad en los nombramientos — artículos 329 y 330 de la LOPJ—.

\footnotetext{
${ }^{1}$ Un análisis sobre el contenido de la independencia judicial, en su evolución del Estado liberal al Estado constitucional de Derecho, así como su plasmación en España, lo hemos realizado en LOUSADA AROCHENA, J. F. y RON LATAS, R. P., La independencia judicial, Editorial Dykinson, Madrid, 2015. ${ }^{2}$ Nos permitimos remitir al lector o lectora a RON LATAS, R. P. y LOUSADA AROCHENA, J. F., La independencia judicial en la historia constitucional de España (1808-1975), Punto Didot, Madrid, 2017.

${ }^{3}$ De nuevo nos permitimos remitir al lector o lectora a LOUSADA AROCHENA, J. F. y RON LATAS, R. P., El Consejo General del Poder Judicial, actualmente pendiente de publicación en Punto Didot.
} 
Pero, tras establecer que "la provisión de destinos de la Carrera Judicial se hará por concurso, en la forma que determina esta Ley", el artículo 326, apartado 2, de la LOPJ agrega "salvo los de Presidentes de las Audiencias, Tribunales Superiores de Justicia y Audiencia Nacional y Presidentes de Sala y Magistrados del Tribunal Supremo". Tales salvedades, a las que hay que añadir las Presidencias de las Salas de la Audiencia Nacional, las Presidencias de las Salas de los Tribunales Superiores de Justicia de las Comunidades Autónomas, y los Magistrados de las Salas de lo Civil y Penal de los Tribunales Superiores de Justicia propuestos por las Asambleas legislativas de las Comunidades Autónomas, se conocen como nombramientos discrecionales.

Y es que, con relación a tales cargos, la LOPJ atribuye al CGPJ —en concreto, al Pleno del CGPJ en atención a lo establecido en su artículo 599.1.4 — la propuesta de nombramiento de las Presidencias de Sala del Tribunal Supremo ${ }^{4}$, así como de sus Magistrados $^{5}$, de la Presidencia de la Audiencia Nacional ${ }^{6}$, de la Presidencia de los Tribunales Superiores de Justicia ${ }^{7}$, y de las Presidencias de las Salas de la Audiencia Nacional y de las Salas de los Tribunales Superiores de Justicia de las Comunidades Autónomas $^{8}$, y los Magistrados de las Salas de lo Civil y Penal de los Tribunales Superiores de Justicia propuestos por las Asambleas Legislativas de las Comunidades Autónomas ${ }^{9}$, y de la Presidencia de las Audiencias Provinciales ${ }^{10}$, exigiendo en cada caso algunas condiciones particulares $y$, en especial, exigiendo una cierta antigüedad ${ }^{11}$.

\footnotetext{
${ }^{4}$ Los Presidentes de Sala del TS se nombrarán, por un período de cinco años, a propuesta del CGPJ, entre Magistrados de dicho Tribunal que cuenten con tres años de servicios en la categoría (art. 342 LOPJ).

${ }^{5}$ De cada cinco plazas en el Tribunal Supremo: (1) Dos corresponderán a magistrados que hubieren accedido a la categoría mediante las correspondientes pruebas de selección en el orden jurisdiccional civil y penal o que las superen ostentando esa categoría, o, en función del orden jurisdiccional, dos a magistrados especialistas en el orden jurisdiccional contencioso-administrativo y social o que pertenezca en este último caso al extinguido Cuerpo de Magistrados de Trabajo. En este turno se exigirán 15 años en la Carrera y solo cinco en la categoría. A los efectos de la reserva de plazas en el orden jurisdiccional civil, los magistrados que hubiesen superado las pruebas de especialización en materia mercantil se equipararán a los que hubiesen superado las pruebas de selección en el orden jurisdiccional civil. (2) Otras dos corresponderán a magistrados con diez años, al menos, de servicios en la categoría y no menos de quince en la Carrera. (3) La quinta a abogados y juristas de prestigio que, cumpliendo los requisitos establecidos para ello, reúnan méritos suficientes a juicio del CGPJ y hayan desempeñado su actividad profesional por tiempo superior a quince años preferentemente en la rama del Derecho correspondiente al orden jurisdiccional de la Sala para la que hubieran de ser designados (véanse arts. 342 a 345 LOPJ).

${ }^{6}$ La Presidencia de la AN se proveerá por el CGPJ, por un período de cinco años, entre Magistrados con quince años de servicios prestados en la categoría, que reúnan las condiciones idóneas para el cargo, en los términos previstos en esta Ley para los Presidentes de los TSJ (art. 335.2 LOPJ).

${ }^{7}$ Los Presidentes de los TSJ se nombrarán por un período de cinco años a propuesta del CGPJ entre Magistrados que hubieren prestado diez años de servicios en la categoría, lo hubieren solicitado y lleven, al menos, quince años perteneciendo a la Carrera Judicial (art. 336.1 LOPJ).

${ }^{8}$ Las plazas de Presidente de Sala de la AN, así como las de Presidente de Sala de los TSJ, se proveerán, por un período de cinco años, a propuesta del CGPJ, entre Magistrados que hubieren prestado 10 años de servicios en esta categoría y ocho en el orden jurisdiccional de que se trate. No obstante, la Presidencia de la Sala de Apelación de la Audiencia Nacional se proveerá entre magistrados con más de 15 años de antigüedad en la carrera que hayan prestado servicios al menos durante 10 años en el orden jurisdiccional penal, prefiriéndose entre ellos a quien ostente la condición de especialista (art. 333.1 LOPJ).

${ }^{9}$ En las Salas de lo Civil y Penal de los TSJ, una de cada tres plazas se cubrirá por un jurista de reconocido prestigio con más de 10 años de ejercicio profesional en la comunidad autónoma, nombrado a propuesta del CGPJ sobre una terna presentada por la Asamblea legislativa (art. 330.4 LOPJ).

${ }^{10}$ Los Presidentes de AAPP serán nombrados por período de cinco años, a propuesta del CGPJ, entre los Magistrados que lo soliciten de entre los que lleven diez años de servicios en la Carrera (art. 337 LOPJ).

${ }^{11}$ Con relación a las plazas de nombramiento discrecional que exigen cierta antigüedad, el Tribunal Supremo viene concluyendo (por todas, STS, Sala 3ª de 29 de mayo de 2006 [rec. núm. 309/2004]) que presentan "un perfil mixto, en cuanto que su cobertura resulta de la apreciación de elementos objetivos y reglados, junto con otros que requieren valoraciones subjetivas y de difícil encaje en módulos o baremos
} 


\section{UN INICIAL DESARROLLO REGLAMENTARIO REFORZADO CON UN CONTROL JUDICIAL LIMITADO A VERIFICAR LAS CONDICIONES OBJETIVAS PERO SIN ENJUICIAR LA DISCRECIONALIDAD TÉCNICA.}

Apoyándose en lo dispuesto en el (ya derogado) artículo 110 de la LOPJ — que en su redacción originaria habilitaba al CGPJ para dictar reglamentos sobre su personal, organización y funcionamiento, dentro de lo cual implícitamente se entendía incluido el procedimiento para la cobertura de plazas y cargos de nombramientos discrecional, y, desde la Ley Orgánica 16/1994, de 8 de noviembre, habilitaba expresamente al CGPJ para dictar reglamentos en materia de forma de solicitud de provisión de plazas y cargos de nombramiento discrecional_- el CGPJ aprobó en su momento un Reglamento de Organización y Funcionamiento ${ }^{12}$, entre cuyos contenidos se encontraba precisamente el procedimiento de nombramientos discrecionales — que acometía en arts. 46, 72 y 74 -

En principio, y según la norma reglamentaria, la decisión de nombramiento de cargos judiciales se dejaba en manos del Pleno del CGPJ, que debía motivar el acuerdo, con expresión de las circunstancias de mérito y capacidad que justificasen la elección de uno de los aspirantes. Pero se permitía al Pleno hacerla por remisión, en lo coincidente, al informe elaborado por la Comisión de Calificación del propio CGPJ. Esta Comisión, que estaba compuesta por cinco vocales del CGPJ — según el ya derogado artículo 134 de la LOPJ_-, enviaba al Pleno "una relación de al menos tres candidatos para el cargo de que se trate" con un informe que debía contener extremos tales como una "exposición general" de los méritos y perfil de los candidatos, o una justificación de la composición de la terna con indicación de las circunstancias apreciadas en sus integrantes que fundamentaran su "superior idoneidad para ocupar la plaza anunciada". Sobre el papel, parecía fuera de toda duda que el sistema arbitrado para la provisión de plazas judiciales de nombramiento discrecional garantizaba la independencia judicial, proveyendo tales órganos de los candidatos más idóneos para el puesto de que se tratase. En suma, un sistema meritocrático en el que para elegir el candidato se ponderaban criterios tales como las "actividades jurisdiccionales y extrajurisdiccionales reveladoras de destacados conocimientos jurídicos y de la aptitud necesaria para el ejercicio de la función jurisdiccional", el cual no parecía pugnar con la necesaria garantía de la independencia judicial, que supone asegurar a los jueces más capaces la ausencia de arbitrariedad en la legítima aspiración de optar a los puestos más altos de la judicatura.

preestablecidos, por más que referidas en todo caso a la idoneidad para el ejercicio de la función y en ningún caso ajenas a las exigencias constitucionales de mérito y capacidad ... En definitiva, el destino no puede configurarse como un puesto de libre designación en el sentido con que habitualmente se utiliza esta expresión en el ámbito de la función pública ni es un puesto que se cubra mediante concurso: - No es un puesto de libre designación en la acepción tradicional, pues una característica del sistema de libre designación como forma de provisión de empleos y cargos públicos es la confianza personal de quien hace el nombramiento en favor del nombrado, que conlleva la libertad de cese o remoción del así designado, notas éstas que no resultan predicables en modo alguno del puesto del que tratamos, que, muy al contrario, justamente por estar ligado al ejercicio de la función jurisdiccional, con las notas de profesionalidad, independencia e imparcialidad que le son inherentes, no puede caracterizarse como un puesto de confianza personal y presenta un sistema reforzado de garantías de permanencia en el cargo para su titular, que le salvaguarda de eventuales remociones basadas en criterios de oportunidad y sólo permite el cese en casos estrictamente tasados. - Pero tampoco es un puesto de concurso, habida cuenta que la valoración última de la idoneidad de los aspirantes es irreductible a un baremo preestablecido".

${ }^{12}$ Mediante Acuerdo de 22 de abril de 1986 (BOE de 5 de mayo de 1986). 
Probablemente el convencimiento de que ello era así $-\mathrm{y}$ acaso también lo fuese en la realidad de las cosas, o no- condujo a la inicial jurisprudencia de la Sala de lo Contencioso Administrativo del Tribunal Supremo a limitarse a controlar la verificación de los requisitos objetivos exigidos para el cargo o puesto discrecional de que se tratase, y, en particular, la antigüedad. En este sentido, una STS (Sala 3 ${ }^{a}$ ) de 11 de julio de 1988 anuló y dejó sin efecto los nombramientos de los Presidentes de las Audiencias Provinciales de Teruel y Cuenca por no cumplir con la antigüedad exigida legalmente, pues el CGPJ computó la que tenían como jueces de distrito, y solo era posible computar esa antigüedad como jueces de distrito desde la entrada en vigor de la Ley 5/1981, de 16 de noviembre, de integración de jueces de distrito en la Carrera Judicial.

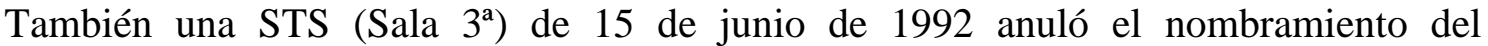
Presidente de la Audiencia Provincial de Murcia. El CGPJ designó a uno de los solicitantes, antiguo juez de distrito, computando, como había hecho en el caso anterior, los años de servicio cumplidos como juez de distrito. Fue recurrido el nombramiento por los otros dos candidatos, y el CGPJ, conocedor de la anterior jurisprudencia, dejó sin efecto su acuerdo, pero, en vez de nombrar a alguno de los otros dos, esperó a cubrir la plaza cuando el primer candidato había cumplido ya los diez años en la Carrera Judicial. El TS anuló y dejó sin efecto este nombramiento porque entendió que la verificación de la antigüedad se debía realizar en el momento en que se había producido la vacante, y no en el momento posterior en que se resolvió su cobertura por el CGPJ.

Igualmente es oportuno citar una STS (Sala $3^{\text {a }}$ ) de 17 de marzo de 1992, que anuló el nombramiento de un Magistrado de Sala de lo Civil y Penal de un Tribunal Superior de Justicia. Aquí lo cuestionado era si el solicitante acreditaba especiales conocimientos de Derecho civil, foral o especial propio de la Comunidad Autónoma. El TS consideró que, en el caso enjuiciado, esos conocimientos no se encontraban acreditados, anulando en consecuencia el nombramiento discrecional. Pero no hizo nombramiento a favor del recurrente, sino que preservó la facultad de designación del CGPJ, al considerar que al TS le compete solo, en virtud del carácter revisor de la jurisdicción contenciosa, efectuar un control de legalidad, pero no sustituir al CGPJ.

De este modo, la potestad de nombramientos discrecionales atribuida legalmente al CGPJ en la LOPJ no se fiscalizaba judicialmente más que en cuanto a la verificación de las condiciones objetivas establecidas legalmente que se debían reunir para el nombramiento discrecional, pero no se controlaba la facultad discrecional del CGPJ, y mucho menos se podía lograr judicialmente la designación del candidato excluido.

\section{DE UN CONTROL JUDICIAL LIMITADO A VERIFICAR LAS CONDICIONES OBJETIVAS A UN CONTROL JUDICIAL CON ENJUICIAMIENTO DE LA DISCRECIONALIDAD TÉCNICA.}

En los años inmediatamente posteriores a la promulgación de la LOPJ no existen, pues, pronunciamientos del TS que duden de la legitimidad de las previsiones normativas. Y hemos de decir que así fue hasta una serie de decisiones de la Sala $3^{a}$ del TS que cuestionaron la validez del método empleado en la provisión de plazas de nombramiento discrecional. Se trata de sentencias dictadas desde 2006. El aviso a navegantes se produjo algo antes con una STS (Sala $3^{\text {a }}$, en Pleno) de 3 de marzo de 
$2005^{13}$, en la que se resolvía el nombramiento de un Magistrado de la Sala $2^{\mathrm{a}}$ del TS. Entonces, a propósito de la motivación de los nombramientos discrecionales, que no era el problema central que se debatía, la resolución avisó que la jurisprudencia se hallaba en tránsito, lo que significaba que no había llegado todavía a conclusiones firmes, pero indicaba que se estaban planteando respuestas diferentes a las que se venían ofreciendo.

La Sentencia que de verdad nos interesa, auténtico leading-case de la nueva corriente jurisprudencial, es una STS (Sala $3^{\mathrm{a}}$ en Pleno, con voto particular) de 29 de mayo de $2006^{14}$, y diversos Autos (también de Pleno) dictados para su ejecución ${ }^{15}$. La plaza en discusión era la Presidencia de la Sala de lo Penal de la Audiencia Nacional.

En esta STS se reconoce que el sistema legal es un sistema "fruto de una valoración integral o global del candidato (de sus aptitudes personales, su formación jurídica y su experiencia profesional) no reconducible a criterios previamente baremados, en cuya apreciación no puede negarse al órgano de selección un amplio margen de libertad de apreciación". No duda el Alto Tribunal, en consecuencia, de la "plena legitimidad constitucional de la amplia libertad de apreciación de que goza el CGPJ a la hora de efectuar nombramientos [discrecionales]", llegándose incluso a afirmar que "no sería fácilmente comprensible que siendo uno de los fines de los constituyentes al erigir tan complejo órgano constitucional el de asegurar la independencia en el nombramiento de los jueces y magistrados, se le hubiese limitado a convertirse en una mera Comisión calificadora de automática y objetivada computación de méritos, excluyéndole de hacer valoraciones de conveniencia institucional, a él confiadas precisamente por razón de su origen, rango y compleja composición". De este modo, el Tribunal Supremo acepta la discrecionalidad técnica en el nombramiento de cargos judiciales, hasta el punto de que la misma se objetiva como un método más garantista de la independencia judicial que el meramente objetivo de antigüedad.

Pero, eso sí, para el TS ello también impide "aceptar como jurídicamente correctos aquellos nombramientos que reflejen exclusivamente el favorecimiento de algunos jueces, entendido el término en el sentido de hacerlo gratuitamente, sin conexión con la finalidad de un correcto entendimiento de la independencia de todos y cada uno de los titulares del Poder Judicial del Estado y prescindiendo en suma de sus específicas aptitudes, méritos y capacidades en el desempeño de la función jurisdiccional". Existe, en efecto, un límite en materia de nombramientos, un elemento de limitación de los poderes del CGPJ, incluso en el caso de ejercicio de sus facultades de libre apreciación para la provisión y cobertura de destinos entre jueces y magistrados previamente delimitados por la Ley en función de un determinado número de años de servicio, que sería el art. 122 CE. Cuando el artículo 122.1 CE establece que "la ley orgánica del poder judicial determinará la constitución, funcionamiento y gobierno de los Juzgados y Tribunales, así como el estatuto jurídico de los jueces y magistrados de carrera, que formarán un Cuerpo único", está recogiendo todas las notas rectoras de un sistema de carrera, "entendido como un cursus honorum en el que se desarrolla una progresión profesional vertebrada en torno a tres conceptos: el estatuto, el Cuerpo y la carrera.

\footnotetext{
${ }^{13}$ Rec. núm. 260/2004

${ }^{14}$ Rec. núm. 309/2004.

${ }^{15}$ Sobre esta STS, y los autos en su ejecución, así como la jurisprudencia subsiguiente, véase MURILLO DE LA CUEVA, P.L., "El control de la actividad del Consejo General del Poder Judicial en materia de nombramientos y de régimen disciplinario en la jurisprudencia reciente", en Jurisprudencia contenciosoadministrativa (2005-2007): análisis crítico, Cuadernos de Derecho Judicial, núm. 125, 2007.
} 
Progresión o promoción profesional que está igualmente vinculada a los principios constitucionales de igualdad, mérito y capacidad, que resultan proyectables sin reservas sobre los cargos judiciales". La configuración de la carrera judicial como peculiar carrera profesional, en el sentido singular y diferenciado que se ha expuesto, se revela, pues, no como una cuestión inadvertida o intrascendente, sino como una "opción decidida y plenamente consciente de la Constitución, con la finalidad de apurar las garantías de la independencia que está en la base de la actividad jurisdiccional”.

O sea, el CGPJ dispone de un "margen de libertad de apreciación ... no reconducible a parámetros objetivados y predeterminados, [pero que] no puede implicar en modo alguno que la decisión sobre la cobertura de una plaza vacante devenga fruto de un voluntarismo inmotivado y carente de cualquier posibilidad de control". De este modo, en este tema no cabe utilizar "criterios de confianza" para la provisión de plazas, basados en "apreciaciones de oportunidad política, afinidad personal o adscripción ideológica", y sí "en razones exclusivas de aptitud profesional para el desempeño del puesto concernido, que podrán tener en cuenta, por supuesto, no sólo la formación y experiencia técnico-jurídica, sino también la aptitud personal para la labor de dirección y gestión inherente a la Presidencia de un órgano jurisdiccional colegiado, pero que en todo caso deberán ser explicables y asequibles desde la perspectiva de los principios constitucionales de mérito y capacidad". Se admite así "un amplio margen de valoración discrecional de las aptitudes personales de los aspirantes, pero esa discrecionalidad no puede ser la propia o típica de los criterios habituales de provisión de los puestos directivos situados en los niveles superiores de la Administración Pública, marcados por las notas de la confianza personal y la empatía con el ámbito de la decisión política".

En suma, el TS admite la potestad del CGPJ de libre apreciación y valoración, con un margen amplísimo pero no ilimitado, siendo así límites a esa potestad del CGPJ: "la recta observancia de los trámites procedimentales que preceden a la decisión, el respeto a los elementos objetivos y reglados, la eventual existencia de una desviación de poder ... la interdicción de los actos arbitrarios ... y los que incidan en una argumentación ajena a los criterios de mérito y capacidad, entendido el primero en el sentido de valores ya acontecidos y acreditados en el currículum del candidato y el segundo en el de aptitudes específicas de desempeño eficaz del destino pretendido".

La consecuente estimación del recurso contencioso-administrativo con la consiguiente anulación del acuerdo de nombramiento y la reposición de las actuaciones en el momento en que la Comisión de Calificación debió emitir su informe, dio lugar a una nueva elección, que recayó en el mismo candidato que la anterior y que fue igualmente anulada por Auto del Pleno de 27 de noviembre de 2006, dictado en incidente de ejecución de sentencia. Tal incidente fue promovido por uno de los candidatos que, pese a no haber recurrido el primer nombramiento, consideró que estaba legitimado en cuanto interesado en el procedimiento desde el momento en que, dispuesta por la Sala la retroacción de las actuaciones, pasaba a disfrutar de tal condición. Y alegaba que, al ejecutar la sentencia, la Comisión de Calificación prescindió de sus méritos y, sobre todo, tuvo en cuenta méritos del candidato elegido posteriores a la fecha del nombramiento anulado. Argumentos ambos acogidos en Auto de 27 de noviembre de 2006 (como la STS dictado en Pleno y con un voto particular). 
Un periplo judicial que se entiende, según ha destacado la doctrina científica, por la "muy significativa ... forma en que se plasmó la decisión del CGPJ de elegir a un determinado candidato para la Presidencia de la Sala de lo Penal de la AN": en primer lugar, "la Comisión de Calificación no evacuó el informe sobre los aspirantes incluidos en la terna que elevó al Pleno", en segundo lugar, "se manejaron para uno solo de ellos méritos posteriores a la fecha de presentación de las solicitudes", en tercer lugar, "el acta de la sesión del Pleno en que se produjo la indicada elección no refleja que hubiera un debate sobre los méritos de los distintos aspirantes", y, en cuarto lugar, "se señaló la incoherencia de que los únicos (méritos) apuntados (de los aspirantes) concurrieran, aparentemente, en mayor medida que en el elegido en otro de los candidatos"16.

Otra STS, también del Pleno de la Sala Tercera, también con voto particular, y también de 29 de mayo de $2006^{17}$, dilucidó el recurso interpuesto por el Parlamento Vasco contra el Acuerdo del Pleno del CGPJ que devolvió la terna presentada por esa Asamblea Legislativa, después de que, sometida sin debate previo sobre los candidatos a las cuatro votaciones establecidas reglamentariamente, ninguno alcanzara los votos necesarios. Se acoge parcialmente el recurso porque se considera no ha habido motivación suficiente de por qué los candidatos no eran juristas de reconocido prestigio, y no lo es el simple agotamiento de las votaciones, pero no se obliga al CGPJ — como pretendía el Parlamento Vasco - a que se vote hasta que algún candidato tenga mayoría.

Hay que añadir que, posteriormente, una STS (Sala $3^{\text {a }}$ ) del Pleno de 27 de noviembre de $2006^{18}$ aplicó la misma doctrina respecto del nombramiento de Presidente de la Sala de lo Social del TSJ de Cataluña, y que la STS (Sala $3^{\mathrm{a}}$ ) de la Sección $7^{\mathrm{a}}$ de 30 de noviembre de $2006^{19}$, a propósito esta vez del nombramiento del Jefe de la Sección de Selección de la Escuela Judicial (que, aunque no es un cargo jurisdiccional, si es un nombramiento discrecional), siguieron criterios sustancialmente semejantes.

Otra STS (Sala $3^{\mathrm{a}}$ ), de 27 de noviembre de $2007^{20}$ incidió sobre la necesidad del cumplimiento efectivo y adecuado del trámite previo de informe de la Comisión de Calificación al Pleno, pues es ese informe el que va a suministrar parte sustancial de los datos que permitirán a cada uno de los vocales orientar su voto. En particular, se hace necesario el razonar de forma circunstanciada con una "motivación consistente" que haga jurídicamente asequibles las razones por las que se decidió adjudicar la plaza a un candidato. La STS incide en la necesidad de motivar especialmente los nombramientos para el TS (se trataba de plazas de la Sala 4a del TS) pues la "omisión de una suficiente motivación es mucho más significativa si se tiene en cuenta que se trata de designaciones para Magistrados del TS, ya que en ellas, por ir referidas a la máxima categoría de la carrera judicial, rigen con el mayor nivel de exigencia los principios de mérito y capacidad", debiendo dejar "claramente explicadas y objetivadas las concretas circunstancias de mérito y capacidad con las que justifica su decisión de nombrar a una determinada persona con preferencia sobre los demás aspirantes a la misma plaza”.

\footnotetext{
${ }^{16}$ Pablo Lucas Murillo de la Cueva, "El control ...", cit., p. 135.

${ }^{17}$ Rec. núm. 137/2005.

${ }^{18}$ Rec. núm. 117/2005.

${ }^{19}$ Rec. núm. 153/2003.

${ }^{20}$ Rec. núm. 407/2006.
} 
En definitiva, lo que sostiene la Sala de lo Contencioso-Administrativo del TS (en esta última STS de 27 de noviembre de 2007) es la necesidad de "disipar cualquier sombra de sospecha sobre que la proximidad ideológica, partidaria o simplemente asociativa pueda ser el componente principal de las decisiones que sobre nombramientos judiciales ha de adoptar el CGPJ; y que la justificación y objetivación de los nombramientos judiciales, en los términos de profesionalidad que han sido apuntados, es el mejor camino para ahuyentar aquellos riesgos de sospecha y fortalecer esa confianza social en la Justicia sin la cual no puede hablarse de verdadero Estado de Derecho". Y ello, por una sencilla razón: "la aceptación de que la confianza social en la Administración de Justicia constituye un elemento esencial del sistema de convivencia es hoy un lugar común en la teoría política y la práctica jurisprudencial constitucional; como así mismo son ampliamente compartidas estas ideas: que la mejor funcionalidad democrática de jueces y magistrados la constituye su escrupuloso respeto al Derecho, que la mejor garantía para lograr ese respeto es su alta solvencia profesional y que todo ello, junto a la imagen de neutralidad política que deben presentar los tribunales de justicia, son importantísimos factores para que no quiebre esa confianza social".

\section{EL REGLAMENTO DEL CONSEJO GENERAL DEL PODER JUDICIAL 1/2010, DE 25 DE FEBRERO, SOBRE PROVISIÓN DE PLAZAS DE NOMBRAMIENTO DISCRECIONAL DE LOS ÓRGANOS JUDICIALES.}

El CGPJ, atendiendo al grueso cuerpo jurisprudencial del TS, decidió tomarlo en consideración, aprobando mediante Acuerdo de 25 de febrero de 2010, el Reglamento $1 / 2010$, sobre provisión de plazas de nombramiento discrecional de los órganos judiciales $^{21}$. Se trata de una norma que presenta como objetivo - confesado en su Exposición de Motivos - el de elaborar un reglamento de provisión de plazas "a fin de garantizar la observancia del imperativo constitucional de interdicción de la arbitrariedad de los poderes públicos ... y el respeto al derecho fundamental de acceso en condiciones de igualdad a las funciones y cargos públicos ... produciendo con ello el efecto positivo de mayor transparencia en la provisión de plazas judiciales de carácter discrecional", acudiéndose, entre otras fuentes, "a la línea jurisprudencial de la Sala de lo Contencioso-Administrativo del TS iniciada con ocasión de recursos interpuestos frente a nombramientos discrecionales efectuados a propuesta de este Consejo".

Nos encontramos, pues, con que, en la actualidad, la provisión de plazas judiciales de carácter discrecional cuenta con una norma que se ha esforzado en adecuar el proceso de nombramientos a una serie directrices básicas, con el fin de que se cumplan tanto los principios constitucionales de mérito y capacidad como las pautas marcadas por la Jurisprudencia Contencioso-Administrativa. En este sentido, el proceso de selección del CGPJ se sostiene ahora sobre tres ideas básicas, a saber: (1) la libertad de apreciación que corresponde al CGPJ, en cuanto órgano constitucional con un claro espacio de actuación reconocido; (2) la existencia de unos límites que necesariamente condicionan esa libertad, especialmente el límite que representan los principios de mérito y capacidad; y (3) la significación que se reconoce al requisito de la motivación.

\footnotetext{
${ }^{21}$ Publicado en el BOE de 5 de marzo de 2010.
} 
Con dicho fin, el Reglamento se divide en tres capítulos. En el I, sobre "disposiciones generales", se determina el objeto del Reglamento y su ámbito de aplicación ${ }^{22}$ —donde, por cierto, se efectúa la necesaria distinción entre plazas jurisdiccionales, gubernativas, y jurisdiccionales y gubernativas ${ }^{23}$-, a lo que se añade una relación de principios rectores que han de presidir su concreta aplicación ${ }^{24}$.

El Capítulo II viene a precisar la clase de méritos que el CGPJ puede libremente ponderar y considerar prioritarios para decidir la preferencia determinante de la provisión de las plazas - distinguiendo ahora, como manda la jurisprudencia, entre plazas jurisdiccionales, gubernativas y quinto turno-, aunque con un amplio margen discrecional, ya que el Reglamento se limita a enunciarlos, diferenciando en ocasiones entre méritos preferentes reveladores de excelencia y otros méritos complementarios ${ }^{25}$, dejando así al arbitrio del CGPJ el otorgar más o menos importancia a determinados méritos, aunque es obvio los complementarios no prevalecerán sobre los de excelencia.

Por último, el Capítulo III se refiere al procedimiento para la provisión de plazas, destacando de él que ahora: $\left(1^{\circ}\right)$ la Comisión de Calificación puede recabar informes de los órganos técnicos del CGPJ o de cualquier órgano del Poder Judicial al efecto de una adecuada formación de los criterios de calificación; $\left(2^{\circ}\right)$ la Comisión de Calificación salvo si se trata de plazas del TS - convoca a los solicitantes no excluidos a una comparecencia frente a los Vocales del CGPJ, para que expliquen y defiendan su currículo; $\left(3^{\circ}\right)$ la propuesta de al menos tres candidatos que la Comisión de Calificación

\footnotetext{
${ }^{22}$ Que se ciñe, según su artículo 2.1, a: “a) Presidencias de Sala y Magistrados y Magistradas del Tribunal Supremo. b) Presidencia de la Audiencia Nacional y Presidencias de sus Salas. c) Presidencias de Tribunales Superiores de Justicia de las Comunidades Autónomas y Presidencias de sus Salas. d) Magistrados y Magistradas de las Salas de lo Civil y Penal de los Tribunales Superiores de Justicia propuestos por las Asambleas legislativas de las Comunidades Autónomas. e) Presidencias de Audiencias Provinciales". Véase la no inclusión de las plazas de Magistrados de Salas de lo Civil y Penal de los TSJ.

${ }^{23}$ A efectos del Reglamento, se entenderá por plazas jurisdiccionales las de Magistrados del TS y de las Salas de lo Civil y Penal de los TSJ propuestos por las Asambleas legislativas de las Comunidades Autónomas; por plaza gubernativa la Presidencia de la AN y por plazas jurisdiccionales y gubernativas las Presidencias de Sala del TS, de Sala de la AN, de TSJ y de sus Salas, y de AP (artículo 2.2).

${ }^{24}$ Se formulan, en el artículo 3, unos principios sustantivos y otros procedimentales. En cuanto a los sustantivos, se establece que "las propuestas de nombramientos para provisión de las plazas de carácter discrecional se ajustarán a los principios de mérito y capacidad para el ejercicio de la función jurisdiccional y, en su caso, de la función gubernativa propia de la plaza de que se trate". Aunque en su Exposición de Motivos se afirma que en los nombramientos y designaciones de los cargos de responsabilidad se atenderá al principio de presencia equilibrada de hombres y mujeres, a que se refiere la Ley Orgánica 3/2007, de 22 de marzo, para la Igualdad Efectiva de Mujeres y Hombres, lo cierto es que el artículo 3 del Reglamento no acoge ese principio sino que se limita a indicar que "en la provisión de las plazas a que se refiere este Reglamento se impulsarán y desarrollarán medidas que favorezcan la promoción de la mujer con méritos y capacidad". En cuanto a los principios procesales, se establece que "el procedimiento para la provisión de plazas garantizará, con objetividad y transparencia, la igualdad en el acceso a las mismas de quienes reúnan las condiciones y aptitudes necesarias", siguiéndose "estrictamente lo establecido en la LOPJ, en el presente Reglamento y en las disposiciones que sean de aplicación”. Todos los acuerdos en materia de nombramientos serán suficientemente motivados.

${ }^{25}$ Por ejemplo, véase el artículo 5, sobre "méritos para la provisión de plazas reservadas a los miembros de la Carrera Judicial", donde se distingue: (1) Los "méritos reveladores del grado de excelencia en el estricto ejercicio de la función jurisdiccional", que se valorarán preferentemente, siendo objeto de ponderación el tiempo de servicio activo en la Carrera Judicial, el ejercicio en destinos correspondientes al orden jurisdiccional de la plaza de que se trate, el tiempo de servicio en órganos judiciales colegiados y las resoluciones jurisdiccionales de especial relevancia jurídica y significativa calidad técnica dictadas en el ejercicio de la función jurisdiccional. (2) Los "méritos complementarios (consistentes en) el ejercicio de profesiones o actividades jurídicas no jurisdiccionales de análoga relevancia”, que también se valoran.
} 
debe elevar al Pleno necesita ser motivada mediante valoración en conjunto de los méritos, capacidad y circunstancias de cada aspirante, debiendo contener una serie de elementos valorativos que expresamente se recogen en la norma; y $\left(4^{\circ}\right)$ cada miembro del CGPJ puede proponer otros candidatos distintos de los elegidos por la Comisión de Calificación entre la lista de peticionarios admitidos, siempre de forma motivada, y comunicándolo a la Comisión de Calificación, que los deberá incluir en la relación. Precisar que las referencias a la Comisión de Calificación, desde la Ley Orgánica 4/2013, de 28 de junio, se entienden hechas a la Comisión Permanente, dada la desaparición de aquella y las competencias residuales de esta ex artículo 602 de la LOPJ.

En conclusión, al día de hoy los nombramientos discrecionales en la carrera judicial cuentan con una norma específica cual es el Reglamento 1/2010, sobre provisión de plazas de nombramiento discrecional de los órganos judiciales, aprobado por Acuerdo de 25 de febrero de 2010, cuya finalidad es garantizar que tanto los principios constituciones de mérito y capacidad, como la exigencia jurisprudencial de identificar claramente la clase de méritos que ha considerado prioritarios para decidir la preferencia determinante del nombramiento, explicar la significativa relevancia que ha otorgado a los méritos demostrados en el puro y estricto ejercicio jurisdiccional o en funciones materialmente asimilables, y precisar las concretas circunstancias consideradas en las personas nombradas para individualizar en ellas el superior nivel de mérito y capacidad que les hace a ellas y no otras más acreedoras para el nombramiento. Que esto se lleve a la práctica de manera seria será el verdadero parámetro para verificar si el Reglamento 1/2010 es manifestación de una real preocupación del CGPJ por cumplir con sus funciones constitucionales respetando la independencia judicial o solo un formalismo jurídico que actúe como paraguas frente a las impugnaciones judiciales.

\section{ACCESO DE LAS JUEZAS A LAS ALTAS INSTANCIAS JUDICIALES Y NOMBRAMIENTOS DISCRECIONALES: LAS SOLUCIONES APUNTADAS EN EL PLAN DE IGUALDAD DE LA CARRERA JUDICIAL.}

El tardío acceso de las mujeres a la carrera judicial (les está permitido ser juezas desde 1966, y obviamente aún tardaron unos años en acceder), ha determinado, como es lógico, su tardanza en ocupar los cargos de mayor responsabilidad dentro del Poder Judicial, si bien con relación a los cargos no discrecionales en los cuales prima la mera antigüedad, esta carencia se ha solventado con el simple paso del tiempo — sin desconocer que en algunos tribunales aún hay hoy día una moderada masculinización de algunas Salas o Secciones- Así es que el problema se plantea con los cargos de nombramiento discrecional, dando lugar a un techo de cristal cuya razón última no se encuentra en que las mujeres hayan accedido recientemente a la carrera judicial - de hecho ya llevan accediendo a ella desde hace casi 40 años, últimamente en marcada mayoría numérica, y de hecho también la antigüedad media de las magistradas del TS es superior a la de los magistrados-, ni tampoco en designaciones abiertamente discriminatorias del CGPJ - lo que, por muy poca confianza que se tenga en su política de nombramientos, resulta afirmación claramente excesiva- La razón última de esta infrarrepresentación es que el perfil de un juez de altos tribunales es marcadamente masculino, pues debe estar dedicado a su vida profesional con relegación de su vida personal y familiar, y obligando a veces a una separación geográfica de la sede familiar. 
¿Cómo se resuelve esta carencia de igualdad en los cargos discrecionales? Las soluciones posibles, siendo múltiples y muy variadas, se deben sujetar a las exigencias que, para las acciones positivas, se establecen normativamente. En particular, en el Derecho Comunitario, según el TJUE lo ha interpretado, se han admitido las acciones positivas sin incidencia en el resultado de una manera amplia, así como se han admitido las mal llamadas cuotas de desempate - mal llamadas porque como se verá de seguido se rodean de una serie de garantías para no perjudicar el principio meritocrático, y lo que no perjudica este principio no es nunca una cuota-, pero únicamente si hay una situación de infrarrepresentación, una igualdad sustancial de méritos y una cláusula de apertura según la cual se garantiza a los candidatos masculinos con igual capacitación que las candidatas femeninas que las candidaturas serán objeto de una apreciación objetiva que tenga en cuenta todos los criterios relativos a la persona de los candidatos de ambos sexos e ignore la preferencia concedida a las candidatas femeninas cuando uno o varios de esos criterios hagan que la balanza se incline a favor del candidato masculino, advirtiendo además que dichos criterios no pueden resultar discriminatorios.

Dentro de estos parámetros, se han formulado diversas propuestas, de las que vamos aquí a destacar exclusivamente las que resultan ser de carácter más institucional:

- Establecimiento de una parrilla de méritos (lo que permite a quienes quieren hacer carrera profesional conocer desde el mismo comienzo de esa carrera cuáles son los méritos a valorar, incrementándose la seguridad jurídica y disminuyéndose el riesgo de arbitrariedad) con una preferencia de los méritos basados en el trabajo judicial frente a los méritos de carácter extrajudicial (que son más accesibles a los magistrados varones, menos ocupados que sus compañeras mujeres en las tareas domésticas y de cuidado $)^{26}$.

- Actuaciones necesarias que favorezcan la igualdad de género en los órganos de gobierno de Juzgados y Tribunales y en los nombramientos para la provisión de plazas, de tal manera que la presencia de mujeres sea como mínimo proporcional a la presencia de mujeres en la carrera judicial ${ }^{27}$, lo que no deja de ser un desiderátum muy genérico.

- Cuando concurran varios candidatos con similares méritos se procurará facilitar el nombramiento de mujeres para estos puestos ${ }^{28}$. Se trata de una recomendación un poco

\footnotetext{
${ }^{26}$ Entre las propuestas contenidas en el Documento de Síntesis del Seminario Final, celebrado en Roma del 13 al 15 de diciembre de 2004, como conclusión del Proyecto financiado por la Unión Europea sobre la participación equilibrada de las mujeres y de los hombres en el proceso de toma de decisiones, que fue coordinado por los órganos de gobierno judicial de Italia y con el partenariado de los órganos de gobierno judicial de Francia, España y Rumania, está la de "preparar valoraciones de profesionalidad basadas sobre todo en la experiencia y en la vinculación sobre el campo, con el fin de evitar que las mujeres, mediante una única valoración de los títulos y las oposiciones, se vean fuertemente limitadas y penalizadas durante el resto de su carrera con la inevitable consecuencia de la asunción de puestos de destino más bajos".

${ }^{27}$ El Congreso de los Diputados, en Sesión Plenaria de 2 de diciembre de 2004, aprobó una serie de resoluciones tras la presentación de la Memoria judicial del año 2003, y, entre ellas, "la necesidad de llevar a cabo las actuaciones necesarias que favorezcan la igualdad de género en los órganos de gobierno de Juzgados y Tribunales y en los nombramientos para la provisión de plazas, de tal manera que la presencia de mujeres sea proporcional como mínimo a la presencia de mujeres en la Carrera Judicial".

${ }^{28}$ Por Acuerdo de 22/6/2005 del Pleno del Consejo General del Poder Judicial, entre otras medidas, se acordó "impulsar y desarrollar políticas que favorezcan la promoción de las mujeres con méritos y capacidad en los procesos de nombramiento de cargos gubernativos de la Carrera Judicial (Presidencias de Tribunales Superiores de Justicia y sus Salas y Audiencias Provinciales) y Magistrados del Tribunal Supremo", concretando más específicamente que "para ello, cuando concurran varios candidatos con similares méritos se procurará facilitar el nombramiento de mujeres para estos puestos” (numeral 36.3).
} 
más incisiva pues parece apuntar hacia la preferencia de las candidatas mujeres en el supuesto de similares méritos, pero pierde gas la medida cuando dice que "se procurará facilitar", lo que nos sitúa en el ámbito de la admonición.

- Necesidad de conocimiento previo de los perfiles que se exigen para los cargos discrecionales otorgando transitoriamente preferencia a las mujeres en los casos de iguales o similares méritos, para lo que se hace imperativamente necesaria la motivación de los nombramientos, y atención preferente al currículo jurisdiccional ${ }^{29}$. Se trata de una propuesta que viene a condensar las anteriores: parrilla de méritos; cuota de desempate; motivación de los nombramientos; preferencia del currículo jurisdiccional.

- Realización de estudios sobre los criterios para fundamentar la motivación, ponderando las soluciones dadas en derecho comparado en relación con la cuestión ${ }^{30}$.

Con base en estas propuestas institucionales, el Plan de Igualdad de la Carrera Judicial ${ }^{31}$ aborda la cuestión de la promoción profesional en su Eje II — precisamente así titulado-, donde se afirma, con carácter general, que "la carrera profesional está conformada por el conjunto de oportunidades y expectativas de progreso profesional conforme a los principios de igualdad, mérito y capacidad manifestándose fundamentalmente en el nombramiento de cargos discrecionales, selección para la realización de actividades formativas, en actividades internacionales, etc.", para acabar esta afirmación general con la exigencia -que ya no es tanto afirmación general como medida de carácter concreto- de que "es necesario asegurar en la composición de las ternas la participación equilibrada en términos indicados por la LOIEMH (60-40)".

Para cumplir con estos objetivos, se encargan a la Comisión de Igualdad — según se dice en el Eje II- seis medidas: "(1) Elaboración de informe de Impacto de género que incluya, al menos una relación numérica y porcentual, distribuida por sexo, en las distintas categorías de la Carrera Judicial y en los cargos discrecionales. Se especificará, dentro de los cargos discrecionales, cuántos/as de sus titulares han hecho uso de derechos de conciliación, desagregando a su vez entre mujeres y hombres. (2) Promover la remoción del déficit de presencia equilibrada de mujeres en los cargos de nombramiento discrecional realizados por el Consejo, en actividades docentes, de relaciones internacionales, etc. (3) Impulsar y desarrollar políticas que favorezcan la promoción de las mujeres con méritos y capacidad en los procesos de nombramiento de cargos gubernativos de la Carrera Judicial y Magistradas del Tribunal Supremo. (4) Garantizar que no se toma en consideración, ni directamente ni indirectamente a través de una valoración objetivista del rendimiento, como circunstancia negativa para la promoción profesional, el haber hecho uso de derechos de conciliación, aunque implicasen una situación de excedencia. (5) Actualización permanente de los datos desagregados por género en la página web del poder judicial. (6) Realización de investigaciones o estudios con la finalidad de conocer las modificaciones del déficit de solicitudes y presencias de cargos de mayor responsabilidad en la Carrera Judicial a fin de proponer medidas reglamentarias y legales para alcanzar la paridad".

\footnotetext{
${ }^{29}$ Se trata de una de las conclusiones del Grupo de investigación sobre la discriminación positiva designado por el CGPJ, aunque no es unánime, como recuerda su directora ALEGRET BURGUÉS, M.E., "Conclusiones del Grupo de investigación sobre la discriminación positiva", en La discriminación positiva, Manuales de Formación Continuada, núm. 35, CGPJ, Madrid, 2006, p. 418.

${ }^{30}$ Se trata de la alternativa suscrita por algunos integrantes del Grupo de investigación aludido en nota anterior, según dice ALEGRET BURGUÉS, M.E, “Conclusiones ...”, cit., pp. 418 y 419.

${ }^{31}$ Acuerdo de 14 de febrero de 2013 del Pleno del CGPJ.
} 
A primera vista la redacción del Eje II no aporta demasiadas soluciones: de un lado los objetivos - además de incluir asistemáticamente un inciso final que, con alguna precisión adicional, se pudo incluir como una medida más - se limitan a una definición de carrera profesional; de otro lado, dos de las medidas no pasan de ser reiterativas de la afirmación general ${ }^{32}$, y otras tres se quedan en la visibilización de la desigualdad, así como su alcance ${ }^{33}$, que, siendo paso previo para legitimar una actuación y adoptar la más adecuada al respecto, no supone ninguna solución efectiva.

Sin embargo, una lectura más detenida nos permite vislumbrar en la redacción la existencia de unas ideas de fondo en las que debemos reparar con algo más de detalle:

$1^{\circ}$. En el inciso final de la proclamación de objetivos se afirma —en los que ya hemos dicho e incluso reiterado que no es tanto una afirmación general como una medida de carácter concreto asistemáticamente situada- que "es necesario asegurar en la composición de las ternas la participación equilibrada en términos indicados por la LOIEMH (60-40)". Ciertamente le falta la precisión adicional de cómo ello se debe conseguir, pero atendiendo al propio funcionamiento de las propuestas bajo el formato de terna - sea en su sentido más propio de proponer a tres candidatos, como en el sentido impropio de realizar un primer filtro del cual salen tres o más candidatos, pero en todo caso no de todas las personas que han optado para el puesto-, no resulta difícil considerar cuales pueden ser las precisiones adicionales más idóneas para alcanzar la composición equilibrada de las ternas: garantizar un cuota de cuando menos el $40 \%$ del sexo menos representado - lo que supone, si la terna es de tres, una persona, y en los demás casos el número que más se aproxime a ese porcentaje del $40 \%$ calculado sobre el total de candidatos que integran la terna ( 2 y 2 si son $4 ; 3$ y 2 si 5 ; o 4 y 2 si 6$)$ - . Quizás - dado que se trata solo de la configuración de las ternas - hubiera sido mejor, por ser más incisivo, exigir una absoluta paridad, aunque esto tampoco supondría muchas diferencias en relación con la anterior solución, pues solo afectaría al caso de que fueran 6 los candidatos que integren la terna (en cuyo caso serían 3 de cada sexo).

Conviene destacar que este tipo de medidas que inciden sobre la configuración de las ternas, y no sobre la designación definitiva, no presentan ningún conflicto con el principio meritocrático. Antes al contrario pretenden eliminar las arbitrariedades en un proceso de preselección de las candidaturas que ni está sometido a la transparencia de la designación definitiva, ni está sujeto a unas exigencias tan intensas de motivación.

\footnotetext{
${ }^{32}$ Se trata de la medida numerada 2 -a saber, "promover la remoción del déficit de presencia equilibrada de mujeres en los cargos de nombramiento discrecional realizados por el Consejo, en actividades docentes, de relaciones internacionales, etc."-, y de la medida numerada 3 -a saber, "impulsar y desarrollar políticas que favorezcan la promoción de las mujeres con méritos y capacidad en los procesos de nombramiento de cargos gubernativos de la Carrera Judicial y Magistradas del Tribunal Supremo"-.

${ }^{33}$ Se trata de las medidas numeradas 1 -a saber, "elaboración de informe de impacto de género que incluya, al menos una relación numérica y porcentual, distribuida por sexo, en las distintas categorías de la Carrera Judicial y en los cargos discrecionales (especificando) dentro de los cargos discrecionales, cuántos/as de sus titulares han hecho uso de derechos de conciliación, desagregando a su vez entre mujeres y hombres", 5 -a saber, "actualización permanente de los datos desagregados por género en la página web del poder judicial", y 6 -a saber, "realización de investigaciones o estudios con la finalidad de conocer las modificaciones del déficit de solicitudes y presencias de cargos de mayor responsabilidad en la Carrera Judicial a fin de proponer medidas reglamentarias y legales para alcanzar la paridad".
} 
Naturalmente, su punto débil es no incidir tan incisivamente sobre la designación definitiva, que siempre podrá inclinarse a favor del sexo más representado. Ahora bien, si el número de personas candidatas ha sido especialmente significativo en relación con ambos sexos, debemos admitir que en la terna paritaria se incluirán personas candidatas con sustancial igualdad de méritos, con lo cual debería ser siempre elegida la persona del sexo menos representado, salvo en el caso de haber motivos para la elección de la persona del otro sexo que sean además ajenos al sexo. Estaríamos ante una variante aplicativa del mecanismo de las llamadas cuotas de desempate admitidas en la jurisprudencia comunitaria. La cláusula de apertura a favor del candidato del sexo más representado se plasmaría en una exigencia de motivación reforzada para su designación. Hacerlo de otro modo nos situaría en una clara sospecha de discriminación.

$2^{\circ}$. En la medida numerada 4 -a saber, "garantizar que no se toma en consideración, ni directamente ni indirectamente a través de una valoración objetivista del rendimiento, como circunstancia negativa para la promoción profesional, el haber hecho uso de derechos de conciliación, aunque implicasen una situación de excedencia"-, se puede identificar, puesta en relación con la LOIEMH, tanto un aspecto de garantía negativa como un aspecto de garantía positiva. Quizás el aspecto de garantía negativa sea el que más se nos viene a la cabeza, y no es más que la aplicación del artículo 44.1 de la LOIEMH: "los derechos de conciliación de la vida personal, familiar y laboral se reconocerán a los trabajadores y las trabajadoras en forma que fomenten la asunción equilibrada de las responsabilidades familiares, evitando toda discriminación basada en su ejercicio". Pero hay un aspecto de garantía positiva que se trasluce del texto, y en el cual nos detendremos: el valor curricular de los cuidados.

Frente a la discusión general de si se debe atribuir un valor curricular a los cuidados a efectos de promoción profesional, la respuesta, desde una perspectiva jurídico positiva, debe ser afirmativa en la medida en que el artículo 57 de la LOIEMH ${ }^{34}$ establece que "en las bases de los concursos para la provisión de puestos de trabajo se computará, a los efectos de valoración del trabajo desarrollado y de los correspondientes méritos, el tiempo que las personas candidatas hayan permanecido en las situaciones a que se refiere el artículo anterior" (donde se regulan permisos relacionados con la protección a la maternidad y la conciliación de la vida personal, familiar y laboral).

Tal respuesta jurídico positiva se justifica en una doble finalidad: una es el aprovechamiento de las habilidades adquiridas en el ejercicio de derechos de conciliación a los efectos de un mejor desempeño del cargo de que se trate, lo que exige, obviamente, que aquellas habilidades presenten relación con este cargo; y la otra es la compensación por el tiempo dedicado a la conciliación frente a las demás personas aspirantes que durante ese tiempo han podido engordar sus currículums, siendo esta una justificación válida cualquiera que sea el cargo de que se trate, aunque, si esta no aparece unida a la anterior, la fuerza legitimadora de la medida es sensiblemente menor.

Su aplicación a la Carrera Judicial, que se limitaría a los cargos discrecionales, no es sencilla cuando se trate de cargos con mayor peso jurisdiccional que gubernativo, pues como no existe una relación directa entre las habilidades organizativas que el ejercicio

\footnotetext{
${ }^{34}$ Que se sitúa en la línea de "reconocer las competencias adquiridas en el seno del hogar y de la familia" a que se alude en el artículo 2.n) de la Recomendación 87/567/CEE de 24 de noviembre de 1987 de la Comisión de la Comunidad Económica Europea, sobre la formación profesional de la mujeres.
} 
de la conciliación ha podido desarrollar en la persona candidata y las competencias del cargo, una medida de estas características solo estaría justificada con una finalidad compensadora. Por ello, es más factible en los cargos de peso gubernativo.

Fuera del ámbito de nombramientos de la Carrera Judicial, pero aún dentro del ámbito del CGPJ, nada impide la valoración curricular de los cuidados, junto a otras valoraciones, cuando se trate de un cargo de gestión administrativa; en este sentido, la conciliación es mérito en la fase de concurso para el ingreso en el Cuerpo de Letrados ${ }^{35}$.

$3^{\circ}$. Por último, y en la medida numerada $6-$ a saber, realización de investigaciones o estudios con la finalidad de conocer las modificaciones del déficit de solicitudes y presencias de cargos de mayor responsabilidad en la Carrera Judicial a fin de proponer medidas reglamentarias y legales para alcanzar la paridad"-, se puede identificar una preocupación esencial, y es la de que en muchas ocasiones no hay mujeres entre las personas solicitantes. Aquí es donde se manifiesta el real problema de fondo: no se trata solo de que se nombren más hombres que mujeres cuando ambos sexos concurren a un mismo cargo, sino de que nunca concurren a un mismo cargo todas las mujeres capacitadas para hacerlo, y ello es así tanto si no concurre ninguna mujer, como en el caso de que concurran algunas mujeres, pero no todas las capacitadas.

No es difícil dar una respuesta - al menos en términos meramente teóricos, y pendientes de alguna constatación práctica, que es precisamente la medida que se adopta en este numeral 6 del Eje II del Plan de Igualdad-: el modelo de juez sigue construido en gran medida sobre un patrón masculino. Lo que otras veces -y discúlpeseme si nos reiteramos - hemos llamado "un juez sacerdote dedicado a sus funciones y subordinando a ellas su vida personal y familiar, obligando a su mujer a seguirlo en su periplo vital"36. Y esto conecta con reformas de más amplio calado ${ }^{37}$.

\footnotetext{
${ }^{35}$ Según el Acuerdo de 29 de mayo de 2014, del Pleno del CGPJ, por el que se aprueban los criterios del concurso-oposición para el ingreso en el Cuerpo de Letrados, BOE de 9.7.2014, la fase de concurso que tendrá carácter eliminatorio, siendo necesario obtener en ella un mínimo de 22 puntos para poder acceder a la fase de oposición, y con un máximo de puntos atribuibles en razón de los méritos alegados en el concurso de 42. Entre los méritos a considerar se contemplan méritos académicos, escritos y publicaciones, actividad profesional, superación de otras oposiciones para el ingreso en un cuerpo incluido en el Subgrupo A1 de las distintas Administraciones Públicas, conciliación e igualdad, y conocimiento de la lengua oficial propia de alguna Comunidad Autónoma. Con respecto al mérito "conciliación e igualdad", se valorarán con un máximo de 5 puntos las siguientes situaciones: (1) El cuidado de hijos dentro de los cinco años anteriores a la convocatoria de las pruebas, ya lo sean por naturaleza como por adopción o acogimiento permanente o preadoptivo, siempre que tengan menos de doce años, se valorará con 0,5 puntos por año; si son varios los hijos se incrementa 0,2 puntos por cada año de cuidado del segundo o sucesivo hijo. (2) El cuidado, dentro de los cinco años anteriores a la convocatoria de las pruebas, de un familiar de hasta el segundo grado inclusive de consanguinidad o afinidad siempre que, por razones de edad, accidente, enfermedad o discapacidad no pueda valerse por sí mismo y no desempeñe actividad retribuida, se valorará con 0,3 puntos por año; si son varios los familiares, se incrementa 0,1 puntos por cada año de cuidado del segundo o sucesivo familiar.

${ }^{36}$ La expresión "juez sacerdote" la hemos usado en Lousada Arochena, J. F., "La maternidad y la conciliación en la ley de igualdad, y en especial su regulación para la Carrera Judicial", coordinado por María Elósegui Itxaso, Políticas de género, Cuadernos de Derecho Judicial, tomo V, 2007, págs. 53-126.

${ }^{37}$ Un reciente estudio con propuestas para mejorar la igualdad y la conciliación en la Carrera Judicial es La protección social de la Carrera Judicial, coordinadores Martínez Moya, J. / Sáez Rodríguez, M. C., y autores Lousada Arochena, J. F. / Lluch Corell, F. / Bellido Aspas, M. / Cavas Martínez, F. / Delgado Echevarría, C. / De Rada Gallego, I. / Burgos Herrera, E. / Renedo Juárez, C., BOE, Madrid, 2018.
} 


\section{ULTIMAS TENDENCIAS MARCADAS EN LAS SENTENCIAS DEL TRIBUNAL SUPREMO SOBRE NOMBRAMIENTOS DISCRECIONALES DENTRO DE LA CARRERA JUDICIAL.}

Dictadas con posterioridad al Reglamento 1/2010, sobre provisión de plazas de nombramiento discrecional de los órganos judiciales, y al Plan de Igualdad de la Carrera Judicial, nos corresponde finalmente abordar las últimas sentencias sobre la materia dictadas por la Sala de lo Contencioso-Administrativo del TS, que analizaremos siguiendo generalmente un orden cronológico para verificar la evolución y cómo van confluyendo en ellas todas las temáticas tratadas con anterioridad con otras más nuevas derivadas de aquellos instrumentos normativos, y muy en particular con la temática de la igualdad de los sexos, que ya aparece como un tema novedoso y a la vez recurrente.

(I) La primera de las Sentencias a analizar es la STS (Sala $3^{\text {a }}$, con votos particulares) de 3 de febrero de $2011^{38}$, en la que se discutía una plaza de Magistrado en la propia Sala $3^{\text {a }}$ del TS. Se trata de una Sentencia autocomplaciente pues el TS acepta y aplica sin mayores disquisiciones su anterior doctrina pasada por el tamiz del Reglamento 1/2010. En principio, se dice que la exigencia de motivación resulta básica y esencial cuando de nombramientos discrecionales se trate, por cuanto que la misma es resultado del "amplio debate entablado en la sociedad sobre el funcionamiento de la Administración de Justicia y el cúmulo de críticas dirigidas contra ella por las disfunciones que padece". De este modo, "la clara expresión de que la valoración de la profesionalidad es el criterio preferente al que responden los nombramientos de los altos cargos judiciales, la transparencia en este punto, por fuerza redundará en el fortalecimiento de la imprescindible confianza que a los ojos de los ciudadanos han de merecer el [TS] y los demás tribunales de justicia y producirá el mismo efecto para el CGPJ con la consecuencia añadida, en este caso, de que los miembros de la Carrera Judicial podrán comprobar que el esfuerzo, el afán de mejora y la dedicación profesional son los factores que cuentan en la promoción a la más alta instancia jurisdiccional a la que pueden aspirar, comprobación que no será posible si no se respetan las reglas sobre la motivación, con independencia de la valía del nombrado".

Tras esta declaración de intenciones, y florida justificación de la reforma operada en el ámbito de los nombramientos discrecionales dentro de la carrera judicial, el TS entra en el caso concreto, y aunque el propio TS reconoce que la parte impugnante presenta un "alto nivel de formación jurídica y ... amplia experiencia jurisdiccional ... que expresan una carrera profesional brillante", utiliza precisamente esa superioridad curricular para afirmar que "el procedimiento para proveer las plazas de magistrado ... previsto en la LOPJ no es un concurso de méritos sujeto a baremo". Por el contrario, "tiene la naturaleza singular que le atribuye la posición propia del TS y la de órgano constitucional encargado del gobierno del Poder Judicial que corresponde al Consejo y, dentro de él, asegurado el respeto a los límites representados por la exigencia de motivación y a los demás elementos reglados, juega su libertad de apreciación, mientras no se transgreda el principio de interdicción de la arbitrariedad". Esto significa, para el $\mathrm{TS}$, que los factores cuantitativos, en principio, "no son determinantes y que juegan principalmente los cualitativos". De este modo, "no hay razón para concluir que un determinado número de años de ejercicio o la más prolongada permanencia en un órgano de la jurisdicción o haber sido ponente de un número concreto de sentencias, por

\footnotetext{
${ }^{38}$ Rec. núm. 137/2010.
} 
seguir con los ejemplos anteriores, se ha de transformar necesariamente en factor de preferencia. O para afirmar que optar, en los términos en que lo ha hecho el CGPJ en este caso, por un aspirante menos antiguo implica falta de proporción y arbitrariedad".

Parece así que la exigencia de motivación acaba resultando ser una mera formalidad sin excesivas exigencias y sin necesidad de que una motivación suficiente se identifique con una motivación exhaustiva. Y así lo viene a afirmar el primero de los dos votos particulares que acompañan a la resolución del TS, en el que se parte de la base de que "para hacer nombramientos discrecionales, mantuvimos que los méritos de referencia a tener en cuenta para ocupar el cargo de Magistrado del [TS] habrían de ser esencialmente los de solvencia y excelencia en el ejercicio de la estricta función jurisdiccional", lo que no se cumple si, como es aquí el caso, se da preferencia a un magistrado con un número en el escalafón judicial muy inferior al de otros candidatos, pues "en principio, saltos escalafonales tan pronunciados como el acontecido en este caso precisarían para ser justificados de una argumentación más específica y motivada que la ... (de calificar como) meramente cuantitativos los datos relativos al tiempo de ejercicio de la jurisdicción y a la posición escalafonal", con lo cual estos datos escalafonales "se desvalorizan hasta un límite que prácticamente los hace inocuos". Concluye así el voto particular que "una diferencia tan acusada en el tiempo de servicios y en el orden escalafonal transmite una idea de mayor experiencia en aquel desempeño (de funciones jurisdiccionales) a favor de la recurrente que no puede ser absorbida por una alusión genérica a la excelencia profesional de ambos aspirantes, que liberaría al Consejo de expresar algún motivo explícito para preferir al notoriamente más moderno".

En el segundo de los votos particulares, el Magistrado discrepante incluso llega a afirmar que "las motivaciones pueden ser, y de hecho lo son en ocasiones, hipócritas".

(II) Hay dos sentencias posteriores, ambas referidas a nombramientos de Presidente de la Sala de lo Social de un TSJ, en las cuales el TS se manifiesta reacio a admitir el déficit de motivación como causa de nulidad del acto recurrido, de manera que, por regla general, la existencia de motivación, por escueta que fuera, bastaría para avalar el nombramiento. La STS (Sala $3^{\mathrm{a}}$ ), de 7 de marzo de $2011^{39}$ afirma que "en el presente caso no existe un déficit de motivación, pues las razones por las que ha sido nombrado (un candidato y no el recurrente) ... constan en el acto recurrido y las ha podido combatir el recurrente a lo largo del proceso judicial". Y el TS de nuevo insiste en que "no estamos ante un concurso de méritos propiamente, previamente tasados, aunque en la resolución del procedimiento de selección hayan de aplicarse los principios de mérito y capacidad, pero reconociendo al CGPJ un margen de apreciación". De ahí que se concluya que, "(como) en el presente caso nos encontramos con dos candidatos cuya capacidad y excelencia para ocupar la plaza de Presidente de Sala de lo Social está acreditada ... el acuerdo recurrido se mueve dentro del margen de discrecionalidad que hay que reconocer al CGPJ, para, respetando los principios de mérito y capacidad, poder elegir al candidato que a su juicio es más idóneo para el cargo de Presidente de Sala".

Otro ejemplo es la STS (Sala $3^{\text {a }}$ ) de 12 de abril de $2011^{40}$. El CGPJ dio las siguientes razones para el nombramiento de un candidato: "Se ha tenido en cuenta ... en primer término su larga trayectoria profesional dedicada al orden social del Derecho

\footnotetext{
${ }^{39}$ Rec. núm. 570/2009.

${ }^{40}$ Rec. núm. 261/2009.
} 
principalmente como abogado (durante quince años) y con posterioridad como Magistrado (durante otros dieciocho). El prestigio acumulado a lo largo de estos años ha de ser objeto de atención, constando en el CGPJ la acreditación debida sobre el magnífico funcionamiento de los órganos judiciales de los que ha resultado titular el aspirante nombrado, así como la calidad de sus resoluciones judiciales. Considerando ambos extremos resulta colmada la idoneidad profesional que ha de contar como primer pilar para sustentar este nombramiento. La faceta que define su formación científica se ve reforzada con los estudios y publicaciones que acredita, valorados debidamente por el Pleno". Para el TS “el acto está suficientemente motivado, aun cuando los motivos puedan combatirse por el recurrente, siendo constatables las razones por que el CGPJ ha optado por el candidato finalmente nombrado en relación con los demás aspirantes".

Un punto crítico de esta STS es que ha relativizado la virtualidad invalidante de la ausencia de motivación en relación con los candidatos excluidos de la terna a la que se refiere el art. 16.5 del Reglamento 1/2010. Aunque reconoce que "desde las primeras sentencias recaídas en esta materia de control de los actos de nombramiento discrecional del CGPJ hemos venido manteniendo la necesidad de que el Consejo señale los motivos por los que prefiere a unos candidatos en la terna sobre otros, y que esta exigencia ha venido a convertirse en norma, articulo 16.5.d) del Reglamento 1/2010", acaba concluyendo que "la ausencia de esta motivación previa no implica el desconocimiento de los méritos por parte del Pleno del Consejo, al que se le traslada toda la documentación, y en cualquier caso no conlleva necesariamente la invalidez del acuerdo, sino tan solo en tanto haya causado indefensión al recurrente", lo que, a juicio del TS, no ocurre en el caso enjuiciado porque "los méritos (del recurrente) han podido llegar a conocimiento de la Comisión de Calificación y del Pleno y este los ha conocido desde luego en el momento de resolver el recurso de reposición, pues el recurrente fundamentaba el mismo precisamente en el contraste de méritos entre el mismo y el elegido, entre otras cuestiones jurídicas". O sea, la ausencia de motivación de la exclusión de la terna solo invalida el acto cuando hay indefensión, y esta no la hay nunca cuando se recurre el acuerdo de nombramiento. Ergo la ausencia de motivación de la exclusión de la terna nunca conducirá a la nulidad del acuerdo de nombramiento.

(III) La siguiente Sentencia de la saga, que es la STS (Sala $3^{\mathrm{a}}$ ) de 31 de octubre de $2011^{41}$, presenta una notable particularidad: no se impugna un concreto nombramiento discrecional, sino el Reglamento 1/2010. Se trataba de una demanda interpuesta por ocho Magistradas que se ha construido sobre dos grandes clases de razones — que se acaban entrelazando- en orden a solicitar la nulidad del Reglamento.

Una primera clase de razones impugnatorias se encontraba que el Reglamento "no permite llevar a cabo el imprescindible control judicial de los nombramientos porque no precisa en qué ha de traducirse la valoración de los méritos exigidos" pues "los términos generales en que se manifiesta el Reglamento dificultan, si es que no impiden, la práctica de dicho control". Para ello sería necesaria "la expresión específica, en el propio Reglamento, de parrillas de valoración, con determinación específica de los méritos que ha de reunir cada aspirante a cada plaza, y con reseña de un mínimo y un máximo de puntos a otorgar por cada uno de los méritos ya especificados en cada convocatoria, pero con sujeción a lo determinado en el Reglamento". Y esa carencia "está llamada a producir situaciones de absoluta e incontrolable discrecionalidad /

\footnotetext{
${ }^{41}$ Rec. núm. 199/2010.
} 
arbitrariedad y llevará a alterar la esencia del principio de igualdad". Las lagunas que aprecian en el Reglamento da como resultado que en el mismo "parece primar el ajuste de los candidatos a lo que se da en denominar ajuste del/la candidata/o a la política judicial del CGPJ, en detrimento de los principios de mérito y capacidad de lo/as solicitantes, creando indefensión al no ser un concepto previamente establecido en la base de la convocatoria, ni reglado, concepto que presenta mayores niveles de inseguridad para cualquier persona aspirante a plaza de nombramiento discrecional".

En este punto, se enlaza con la segunda clase de razones impugnatorias del Reglamento: "la falta de determinación de los criterios en función de los cuales se van a decidir estos nombramientos hace imposible la aplicación, con garantías, de principios recogidos en normas promulgadas en materia de la igualdad entre hombres y mujeres". Al respecto, se trae a colación "la exposición de motivos de la Ley Orgánica 3/2007 y el contenido de sus artículos 6, 11 y 16, el último de los cuales dispone que los poderes públicos procurarán atender al principio de presencia equilibrada de mujeres y hombres en los nombramientos y designaciones de los cargos de responsabilidad que les correspondan", para concluir que el Reglamento "no ha ido en la línea de esta Ley Orgánica en esta materia", y que así "difícilmente puede garantizarse lo previsto en la L.O.”; es más con este Reglamento las recurrentes consideran algo "imposible combatir las discriminaciones directa e indirecta descritas en el artículo 6 de la L.O. 3/2007'. Por último, añaden — con razón- que "no se ha dado ningún valor al informe de impacto de género que obra en el expediente, pues sus recomendaciones no han sido atendidas".

El TS rechazó la demanda. Acerca de la cuestión relativa a la pretensión de que en las normas reglamentarias se incluyan parrillas de valoración de los méritos, la sentencia recuerda que los requisitos relacionados con el mérito y la capacidad el Reglamento 1/2010 recogen la doctrina sentada por el Pleno de la Sala $3^{\text {a }}$ del TS, insistiendo en el argumento de que "los nombramientos llamados discrecionales y, en particular, los de magistrados del Tribunal Supremo, se producen mediante una decisión que descansa en el amplísimo margen de elección que el legislador ha puesto en manos del CGPJ si bien, inmediatamente, la doctrina de la Sala exige que esa elección se fundamente en los principios constitucionales de mérito y capacidad que han de apreciarse en relación directa con las concretas características de la plaza de que se trate y vaya acompañada de una motivación que explique las razones que llevaron, primero, a la Comisión de Calificación a formar la propuesta elevada al Pleno del Consejo General del Poder Judicial y, después, a dicho Pleno a realizar su elección. Requisitos y motivación que, tratándose de plazas jurisdiccionales a proveer entre miembros de la Carrera Judicial, han de descansar de manera, si no exclusiva, sí determinante en los méritos relacionados con el ejercicio de la jurisdicción por los solicitantes de las mismas plasmados en las sentencias que hayan dictado o de las que hayan sido ponentes". Con estos postulados, la sentencia acabará afirmando que "la posición de la demanda descansa en una premisa no demostrada: la inhabilidad del Reglamento para el control judicial de estos nombramientos", ya que "la utilización de conceptos indeterminados no equivale a un fomento de la arbitrariedad, como parece sostener la demanda, ni impide la efectividad de la fiscalización que llevan a cabo los tribunales de justicia”.

Por lo que se refiere a la segunda clase de argumentos utilizados, el TS considera que el art. 3.1 del Reglamento, donde se afirma que "en la provisión de las plazas a que se refiere este Reglamento se impulsarán y desarrollarán medidas que favorezcan la 
promoción de la mujer con méritos y capacidad", resulta más que suficiente para observar el principio de la presencia equilibrada de hombres y mujeres en los cargos judiciales de nombramiento discrecional, ya que esa previsión "se suma a las exigencias en ese sentido derivadas directamente de la Constitución". Asimismo, se afirma sin rubor que "las sugerencias concretas recogidas en el informe de impacto de género ... han sido asumidas en el texto o pueden entenderse atendidas a través del mencionado principio rector". Por cual, "la injustificada discriminación de la mujer será de declarar cuando esta haya sido postergada en iguales condiciones de profesionalidad; o cuando en el concreto proceso de nombramiento de que se trate sean de advertir datos o circunstancias que revelen un trato discriminatorio desde la perspectiva de género".

(IV) Con estos antecedentes, que ponen de manifiesto el hecho de que la exigencia de motivación en los nombramientos discrecionales de cargos judiciales seguía siendo una cuestión no exenta de polémica, el TS, manteniendo sus criterios, los va a justificar con mayor amplitud expositiva en dos SSTS (Sala $3^{\text {a }}$ ), ambas de 1 de junio de $2012^{42}$, ambas del mismo Ponente, y ambas relativas a la Presidencia de un TSJ.

Aunque los recursos fueron desestimados, lo interesante de estas sentencias es que realizan una condensación de la doctrina jurisprudencial, enunciando al efecto las dos exigencias a las que se encuentra obligado el CGPJ, una de carácter sustantivo y otra de carácter formal, a saber: (A) "la exigencia sustantiva consiste en la obligación que tiene el CGPJ, a la vista de las singulares plazas convocadas y los concretos aspirantes que participen en la convocatoria, de identificar claramente la clase de méritos que ha considerado prioritarios para decidir la preferencia determinante del nombramiento; y tiene la obligación también de explicar la significativa relevancia que ha otorgado a los méritos demostrados en el puro y estricto ejercicio jurisdiccional o en funciones materialmente asimilables"; y (B) "la exigencia formal está referida a estas tres obligaciones que también pesan sobre el CGPJ: 1) la de expresar las fuentes de conocimiento que haya manejado para indagar cuáles podrían ser esos méritos en el conjunto de los aspirantes; 2) la de asegurar que el criterio de selección de esas fuentes, cuando se trate de méritos estrictamente jurisdiccionales, ha observado rectamente el principio constitucional de igualdad; 3) la de precisar las concretas circunstancias consideradas en la persona nombrada para individualizar en ella el superior nivel de mérito y capacidad que les hace a ellas más acreedoras para el nombramiento".

Lo más curioso de estas SSTS es que, aunque se afirma que "la motivación es, en definitiva, la exteriorización del cumplimiento de esos límites", se entiende que habrá de considerarse cumplida cuando la actuación del CGPJ haga "bien visibles" (¿?) las razones por las que ha sido preferida la persona candidata finalmente nombrada, y que esas razones sean reconducibles a los principios constitucionales de mérito y capacidad $\mathrm{y}$, también, que revelen que "para decidir el nombramiento se ha otorgado un papel capital al ejercicio jurisdiccional con el nivel de profesionalidad que demande la vertiente jurisdiccional del cargo a que se refiera el nombramiento discrecional".

Pero, y aquí viene lo importante, "esos límites y las exigencias derivadas de los mismos en modo alguno privan de libertad al CGPJ, que la conserva con una gran amplitud, pues lo que hacen es, en primer lugar, acotar lo que es para él una obligación inexcusable y, por ello, el punto a partir del cual deberá desarrollar la libertad que es

\footnotetext{
${ }^{42}$ Rec. núm. $146 / 2011$ y 564/2010.
} 
inherente a la discrecionalidad de su función constitucional de gobierno judicial; y, en segundo lugar, expresar también los confines en que se inician los ámbitos donde dicha libertad puede ser ejercitada". La libertad del CGPJ, para el TS, "comienza una vez que se haya rebasado ese umbral de profesionalidad exigible y tiene múltiples manifestaciones, porque, una vez justificada que existe esa cota de elevada profesionalidad en varios de los candidatos, el CGPJ, en ejercicio de su discrecionalidad, puede efectivamente ponderar una amplia variedad de elementos, todos ellos legítimos, y acoger cualquiera de ellos para decidir, entre esos candidatos que previamente hayan superado el escrutinio de la profesionalidad, quien es el que finalmente debe ser nombrado". Y como no podía ser de otro modo, "tales elementos son muy variados y definen un amplísimo ámbito para que esa libertad pueda efectuarse", debiendo respetarse al CGPJ un "margen de apreciación inherente al juicio de discrecionalidad técnica que significa la definitiva selección y estimación cualitativa de los méritos de los aspirantes que deban encarnar esas clases de méritos que previamente hayan sido elegidos y definidos como prioritarios. Un margen de control que rige los cánones propios de esa discrecionalidad técnica consistentes, como es sabido, en que esos juicios de valor no pueden ser invalidados desde la simple discrepancia y solo procede dejarlos sin efecto cuando se haya debidamente justificado su claro error o abierta arbitrariedad".

Decíamos antes que estas SSTS se referían al nombramiento de Presidente de TSJ, un cargo que - como recuerdan esas SSTS — "no es estrictamente jurisdiccional", pues, aunque se trata de un destino con muy importantes funciones jurisdiccionales, además tiene un claro carácter directivo por llevar inherentes importantes funciones de gobierno y organización. Y esta especial circunstancia le permite al TS establecer cuáles han de ser las directas premisas desde las que ha de ser enjuiciada la suficiencia o no de la motivación que resulta exigible, a saber: 1) por lo que concierne a la capacidad profesional de los candidatos, "un muy elevado nivel de solvencia, pues los TSJ en los litigios sobre Derecho autonómico culminan la organización judicial en el ámbito territorial de la Comunidad Autónoma"; 2) por lo que concierne a la "faceta directiva o gubernativa de esta clase de cargos, la libertad de apreciación y opción del Consejo opera en su nivel máximo", por lo que "es a dicho órgano constitucional al que corresponde definir en cada momento las líneas maestras de la concreta política judicial que ha de exteriorizar la función de gobierno del poder judicial que él tiene expresamente atribuida por imperativo de lo establecido en el artículo 122 de la Constitución", y con ello un "amplísimo margen de apreciación que debe serle reconocido en lo tocante a decidir cuál de los proyectos de gobierno aportados por los candidatos encarna mejor la opción de política judicial del Consejo y, también, cuál de esos candidatos, una vez demostrado que ha superado un razonable umbral de profesionalidad, es el que le parece más idóneo para ejecutar dicha política en el concreto territorio para el que sea nombrado"; 3) por lo que en concreto "hace al canon de motivación exigible en casos como el del concreto cargo directivo que aquí es objeto de polémica, lo decisivo será que estén bien visibles las razones que han llevado al Consejo a tomar su decisión a favor de la concreta persona que ha resultado nombrada".

(V) A la vista de todo lo anterior, el panorama parecía no haber cambiado demasiado: se exige motivación en los nombramientos, pero el margen de discrecionalidad sigue siendo muy amplio, y dicha exigencia puede entenderse cumplida con una motivación meramente genérica e inespecífica. Sin embargo, una STS (Sala $3^{\text {a }}$ ) de 26 de abril de 
$2013^{43}$, nos permitió vislumbrar alguna luz de cambio. En ella, lo que se dilucidaba era una plaza de Magistrado en la Sala de lo Civil y Penal de TSJ, y la Sala acabó anulando el nombramiento. Aunque la decisión final no tuvo que ver con la ausencia de motivación, el TS advierte obiter dicta que "la motivación expuesta en el acuerdo recurrido ... es absolutamente insuficiente para justificar la preferencia del Magistrado nombrado (el recurrido) respecto del preterido (el recurrente). No se indican las circunstancias en las que se sustenta el juicio de valor expresado en el acta del Pleno del CGPJ acerca de que el elegido acredite un mayor conocimiento del Derecho especial o foral de Aragón que el preterido ... No existe una identificación de las publicaciones sobre el Derecho de Aragón que avalen la apreciación del mayor conocimiento del elegido, y sobre todo echamos de menos una explicación justificativa de que el hecho de haber dictado un número significativo de sentencias sobre Derecho especial de Aragón, de las que la Comisión de Calificación destaca por su entidad nueve, no se valore como exponente del especial conocimiento de dicho Derecho y se primen frente a ese ejercicio jurisdiccional publicaciones doctrinales, que ni tan siquiera se concretan".

(VI) Esta línea judicial más exigente en orden a la motivación no constituye un unicum en la doctrina del Tribunal Supremo; es más, la necesidad de motivación en los nombramientos discrecionales va a venir ahora acompañada de determinados criterios a aplicar atendiendo a la incidencia del principio de igualdad de mujeres y hombres. La Sentencia de la Sala $3^{\text {a }}$ del TS que se ocupa de ello tiene es la de 10 de mayo de $2016^{44}$. En ella, el Tribunal debía ocuparse de la impugnación del Acuerdo del Pleno del CGPJ por el que se nombró presidente del TSJ de la Región de Murcia, con la particularidad de que la plaza la discutía una candidata que no había sido nombrada para el puesto.

La STS pone de nuevo sobre la mesa una particularidad que viene distinguiendo la resolución de plazas con perfil gubernativo, como resultan ser precisamente las plazas de Presidente de TSJ, frente a las de naturaleza exclusivamente jurisdiccional, "consistente en que respecto de las primeras se ha acentuado aún más por la jurisprudencia el margen de discrecionalidad de que dispone el CGPJ en orden a su provisión por lo que respecta a la valoración del perfil propiamente gubernativo de la plaza en cuestión", ya que "conlleva no solo la intensa labor técnico-jurídica propia del ejercicio de la función jurisdiccional en ese puesto, sino también la dirección, coordinación y gestión de medios materiales y humanos, para lo que se requieren aptitudes personales que trascienden de los puros conocimientos técnicos y cuya valoración no puede reflejarse en un baremo, por más que se trate en todo caso de aptitudes siempre referidas a idoneidad para el mejor desempeño del puesto y no a aspectos extraños y ajenos al mismo, como la empatía personal o la afinidad política".

Pero lo realmente importante de esta Sentencia es que por fin conecta el artículo 3 del Reglamento 1/2010 acerca de la promoción de la mujer con méritos y capacidad en orden a la provisión de plazas judiciales como la aquí concernida, con la LOIEMH, y singularmente con su artículo 16, que dispone que "los Poderes Públicos procurarán atender al principio de presencia equilibrada de mujeres y hombres en los nombramientos y designaciones de los cargos de responsabilidad que les correspondan". No se olvida además la resolución del Plan de Igualdad de la Carrera Judicial aprobado por el Pleno del CGPJ de 14 de febrero de 2013, que se articula en once ejes de

\footnotetext{
${ }^{43}$ Rec. núm. 298/2012.

${ }^{44}$ Rec. núm. 189/2015.
} 
actuación de los que el segundo se refiere a la "promoción profesional en la Carrera Judicial", contemplándose en el mismo los objetivos de "promover la remoción del déficit de presencia equilibrada de mujeres en los cargos de nombramiento discrecional realizados por el Consejo", y de "impulsar y desarrollar políticas que favorezcan la promoción de las mujeres con méritos y capacidad en los procesos de nombramiento de cargos gubernativos de la Carrera Judicial y Magistradas del Tribunal Supremo".

Sobre esta base, el TS acaba concluyendo que, desde el punto de vista de los méritos susceptibles de mayor objetivación, la demandante estaba en una posición de ventaja sobre el adjudicatario de la plaza en litigio. Siendo así, el TS no duda en afirmar que la elogiosa valoración de los méritos del elegido efectuada por el CGPJ "se presenta visiblemente endeble para sustentar la decisión finalmente adoptada". Para el TS además no cabe sustentar la decisión en el elogio desmedido de uno de los criterios de valoración, alzándose encima de los demás, ya que ello "debe ser explicado, y esa explicación es la que aquí falta por completo". Esto supone, en definitiva que "cuando, como aquí ha acaecido, el peso de la decisión se hace recaer en las consideraciones y criterios más puramente subjetivos, en detrimento de los parámetros objetivados que la misma convocatoria perfiló, eso puede y debe ser explicado cumplidamente a fin de despejar cualquier sospecha de posible arbitrariedad o desviación de poder, en un ámbito como este en el que incluso las apariencias son importantes cuando lo que está en juego es la confianza ciudadana en la recta adjudicación de altos cargos judiciales".

Es más, "hay aquí un factor que sobreabunda en la necesidad de esa motivación, sobre el que la resolución impugnada prácticamente pasa de largo, que es el que impone la obligada toma en consideración del principio de preferencia de las mujeres a la hora de adjudicación de las vacantes cuando estas se hallan en un escenario de igualdad sustancial de méritos respecto de los aspirantes varones". En estas ocasiones, "nos hallamos ante algo más que ante un simple desiderátum o catálogo de buenas intenciones cuya operatividad práctica pueda ser diferida sin más hacia un futuro indefinido, certus an incertus quando"; antes al contrario, "se trata de una normativa que está llamada a tener funcionalidad real, y esa funcionalidad se hace más acuciante cuanto más tiempo va transcurriendo desde que entró en vigor". Por lo tanto, "cuando nos hallamos, como es el caso, ante una aspirante mujer que tiene un perfil de méritos profesionales que se presenta inicialmente por lo menos parejo al del otro aspirante varón, e incluso en algunos relevantes puntos notablemente superior, la decisión final de adjudicar la plaza a este último tiene que ser, con especial énfasis, singularmente explicada. Es verdad que el criterio de la preferencia de las mujeres a igualdad de méritos no opera con rígido automatismo como una norma universal de obligado e incondicionado desplazamiento de los aspirantes varones, pero sí que opera como un principio rector de la decisión que exige que se expliquen cumplidamente, caso por caso, las razones por las que se prescinde casuísticamente de esa regla y se elige finalmente a un aspirante varón en detrimento de la aspirante que presenta un perfil profesional parangonable; y esto, una vez más, falta por completo en el caso examinado".

(VII) Si bien la STS de 10 de mayo de 2016 aparece como un indisimulado incentivo del TS para que el CGPJ utilizase el esfuerzo, el afán de mejora y la dedicación profesional como factores predominantes a tener en cuenta en la promoción profesional de jueces y magistrados, con respeto de las reglas sobre la motivación, ha acabado resultando ser un manual de estilo proporcionado por el TS al CGPJ con la finalidad de 
que sus decisiones puedan traspasar con facilidad el filtro judicial. Y es que el Pleno del CGPJ, ejecutando dicha $\mathrm{STS}^{45}$, vuelve a nombrar al mismo candidato, que a la sazón ya venía desempeñando el cargo de Presidente del TSJ de la Región de Murcia. La impugnación consiguiente es resuelta en la STS de 27 de junio de $2017^{46}$, dictada por el Pleno de la Sala $3^{\text {a }}$ del TS. Como es sencillo suponer, el recurso no prosperó (aunque hay voto particular de hasta trece magistrados). El CGPJ había aprendido.

Al final, el TS acaba avalando la posibilidad de que el Pleno del CGPJ emita una nueva resolución en la que se reitera el nombramiento anterior, adoptando la misma resolución con distinto ropaje. Un ropaje que minusvalora, y prácticamente anula, los méritos de naturaleza jurisdiccional para primar los extrajurisdiccionales, incluidas las funciones asistenciales en el propio Consejo. Ello se consigue dando peso específico a las labores gubernativas a través de la valoración de modo exclusivo y excluyente factores relacionados con la gestión. Y es que, de otro modo, el hecho de que tomar en consideración los méritos jurisdiccionales llevaría necesariamente a la mayoría del CGPJ a tener que efectuar el nombramiento en favor de una candidata no deseada.

Como dijimos, el TS no aceptó las argumentaciones de la parte recurrente. En primer lugar, mediante el recordatorio acerca de que "es doctrina de esta Sala la de que en los nombramientos de carácter discrecional el CGPJ tiene amplísimas facultades de valoración y elección, por lo mismo que (a diferencia del concurso de méritos) este tipo de convocatorias no incluye baremación alguna de los méritos computables". En segundo término, asegura algo que también conocemos: "estas facultades del CGPJ se acrecientan cuando el cargo discrecional de cuya cobertura se trate tiene un componente gubernativo, como lo tiene el de presidente de un TSJ". Y ello le lleva a afirmar al TS, lógicamente, que "la comparación aislada de méritos no signifique negar al Consejo una razonable facultad de valoración del conjunto o una preferencia a uno o algunos de los méritos alegados". O dicho de manera sencilla, basta con apreciar dentro de los méritos del candidato "deseado" alguno que le permita prevalecer frente a los demás candidatos, para encontrar pleno respaldo normativo. Así lo permite el TS, al afirmar que "los artículos 5, 7 y 10 del Reglamento 1/2010, al enumerar los méritos a tener en cuenta para cubrir plazas de Presidentes de los TSJ, no establecen una jerarquía entre los mismos; ni disponen que la falta de alguno de ellos constituya impedimento absoluto para la designación ... [así] la potestad discrecional del CGPJ abarca la de preferir cualquiera de los méritos, para decidir entre esos candidatos que previamente hayan superado el escrutinio de la profesionalidad, quién finalmente debe ser el nombrado".

En consecuencia, "vista la clase de nombramiento que nos ocupa (discrecional) y la naturaleza del cargo de que se trata (Presidente de TSJ, de naturaleza jurisdiccional gubernativa, lo que aumenta, según veíamos, el componente discrecional del nombramiento, según nuestra jurisprudencia), el problema de autos no es de comparación de méritos, sino de motivación, es decir, de que el CGPJ explique las causas por las que efectúa el nombramiento, y que estas sean ciertas y razonables". Y para ello bastará con que el CGPJ, a propósito de un determinado "merito preferencial",

\footnotetext{
${ }^{45}$ Precisemos, en efecto, que en la STS de 10 de mayo de 2016 se había anulado el acuerdo de adjudicación y retrotraído las actuaciones administrativas en el expediente de su razón a fin de que se resolviese por el órgano competente sobre la adjudicación de la plaza mediante resolución debidamente motivada en los términos indicados en la fundamentación jurídica de la sentencia, que ya conocemos.

${ }^{46}$ Rec. núm. 4942/2016.
} 
realice "una explicación cumplida, extensa y razonable". Se trata, además, de argumentos que sirven al TS para avalar la preferencia de género del CGPJ, limitándose a indicar, en consecuencia (tras una brevísima argumentación) que "no se cumple, en consecuencia, el perfil parejo que obligaría a otorgar preferencia a la candidata mujer".

(VIII) Las reflexiones recién apuntadas sirven igualmente cuando de lo que se trata es de nombramientos para cualquiera de las distintas Salas del TS. Un claro y reciente ejemplo de ello lo proporciona una STS (Sala 3 $3^{\text {a }}$ de 20 de noviembre de $2017^{47}$. La plaza en cuestión era la de Magistrado de la Sala $1^{\mathrm{a}}$ del TS, y la razón de la disputa era que el criterio seguido por el CGPJ para el nombramiento había sido el hecho de que el elegido figuraba "con el número 1 en la relación de magistrados especialistas en los asuntos propios de los órganos de lo mercantil, siendo el más antiguo de los que integran la terna". Por ello mismo, uno de los reproches que el recurrente efectuaba era "haberse limitado el Pleno del CGPJ a seguir el uso o costumbre de nombrar para las plazas de especialistas de lo mercantil al Magistrado que ocupa el primer puesto en la relación de especialistas de lo mercantil, en todas las ocasiones ocurridas". Para el TS sin embargo, "ninguna norma limita la potestad del Pleno del CGPJ para concretar su discrecionalidad en un mérito determinado. Si en una, o en varias, o en todas las ocasiones, el Pleno considera que un Magistrado es en principio más apto que otros porque ocupa el primer puesto en la relación de especialistas, y da a esa circunstancia o mérito una importancia decisiva, nada hay que oponer". Se trata "de un criterio que objetiva los nombramientos, porque es claro que el orden de las listas de aprobados significa que unos participantes están mejor preparados que otros (ello explica que durante muchos años, y con plena aceptación de los interesados, el CGPJ dirigiera su discrecionalidad hacia el magistrado más antiguo en la especialidad de lo contenciosoadministrativo; lo que, según es opinión común, redundó en beneficio de la Administración de Justicia)". Como fundamentación de su parecer, el TS acaba afirmando que "esa no es la razón única, pues el acuerdo cita (como hemos visto) otras justificaciones, como su reputada experiencia como generalista en el orden jurisdiccional civil, la calidad de sus sentencias y su elevado número, el ser el magistrado más antiguo de quienes integran la terna, etc., de forma que el Pleno del CGPJ no se limitó pura y simplemente a aplicar la antigüedad en la especialización".

(IX) Una cuestión muy específica — de ahí que la hayamos dejado para el final saltándonos en esta sola ocasión el prometido orden cronológico- se aborda en la STS de 9 de marzo de $2017^{48}$ y en la STS de 10 de marzo de $2017^{49}$ (ambas con voto particular). Se trataba de la Presidencia de la Audiencia Provincial de Barcelona. De nuevo aparecen aquí temas recurrentes: discrecionalidad técnica; parrilla de méritos; igualdad de género. No suponen más que reiteración de criterios anteriores. La cuestión de interés en la que sí nos vamos a detener se refiere a que la impugnante alega haber sido relegada por haber suscrito el llamado "Manifiesto de los 33" en el que 33 personas integrantes de la Carrera Judicial se mostraban partidarios de la celebración de un referéndum acerca de la independencia de Cataluña. Reténgase además que el CGPJ ha negado haber tomado en consideración esa circunstancia para nombrar al otro candidato.

\footnotetext{
${ }^{47}$ Rec. núm. 3934/2015.

${ }^{48}$ Rec. núm. 4603/2016.

${ }^{49}$ Rec. núm. 4602/2016.
} 
Frente a ese nombramiento, se presenta una doble impugnación: por la vía del procedimiento de derechos fundamentales y por la vía del procedimiento ordinario.

Por la vía del procedimiento de derechos fundamentales, la STS de 9 de marzo de 2017 rechaza la demanda partiendo de la premisa de que, aun admitiendo que la firma del "Manifiesto de los 33" fue ejercicio legítimo de un derecho fundamental, de esa premisa solo se sigue que no cabe imponer ninguna sanción (penal o disciplinaria) por esa toma pública de posición, de ahí no se sigue que el órgano constitucional encargado de valorar la idoneidad de los candidatos a plazas judiciales de provisión discrecional no pueda tener en cuenta las actuaciones y manifestaciones de índole política que, aun siendo legítimas, hayan realizado los distintos candidatos. Además, se recuerda que las Presidencias de las Audiencias Provinciales tienen un cometido esencialmente gubernativo, con un componente jurisdiccional muy escaso, lo que no solo acentúa la exigencia de neutralidad política de la persona que ocupe la plaza, sino que además incrementa el margen de discrecionalidad del CGPJ a la hora de determinar quién es el candidato más idóneo. Con respecto a la discriminación por razón de sexo, la recurrente no justifica que la vulneración de las normas legales y reglamentarias que alega tiene una vinculación tal con el artículo $14 \mathrm{CE}$ que permita sostener que lo vulnerado es este último, concluyendo en consecuencia que lo planteado aquí no pasa de ser una cuestión de legalidad ordinaria, que no puede ser abordada en esta vía procesal.

Por la vía del procedimiento ordinario, la STS de 10 de marzo de 2017 rechaza la demanda porque, después de descartar diversos defectos del procedimiento administrativo sin mayor interés a nuestro estudio, porque se da por probado que, una de las razones determinantes de haberse nombrado al otro candidato como Presidente de la Audiencia Provincial de Barcelona fue la de no concurrir en él la inconveniencia para el acceso a tal cargo de la demandante, derivada de la firma del "Manifiesto de los 33", pues, sin que ello incida en la libertad ideológica, el CGPJ puede deducir de aquel hecho la inconveniencia de nombrar a la actora para el cargo de que se trata, en cuya conveniencia o inconveniencia para la Administración de Justicia no puede entrar la Sala. Acto en suma debidamente motivado, subrayándose la dilatada experiencia y especialización del candidato propuesto. Inexistencia además de discriminación por razón de sexo, ya que no se infringen las acciones de carácter positivo en la materia, pues los perfiles profesionales pueden ser parejos, pero hay otras circunstancias diferentes ya explicitadas que han llevado al CGPJ a preferir al candidato propuesto.

Lo realmente llamativo desde un punto de vista estrictamente jurídico de estas SSTS no es tanto que habiliten al CGPJ para tomar en consideración cuestiones ideológicas en cargos gubernativos, como que el TS avale como motivo de nombramiento algo que el CGPJ afirmó expresamente no tomar en consideración. Justamente desde esta perspectiva se han hecho atinadas críticas doctrinales: "La Sala — a petición de nadiese dedicó a explorar los recovecos del expediente administrativo, con la añadida particularidad de que las constancias documentales halladas fueron sometidas a una interpretación psicoanalítica sui generis. Es decir, por encima (por debajo, mejor) de lo que afirmaron, negaron o callaron todos los vocales que sufragaron el Acuerdo (gracias a los que este se aprobó, por tanto), pero siguiendo la sospecha — nada infundada, es verdad - sembrada por vocales que votaron en su contra, la Sala leyó los ocultos pero verdaderos motivos de los primeros: no podía pasarse por alto la firma del Manifiesto y había que otorgar a ese hecho una importancia (negativa) determinante. Ahora bien, si 
estos eran sus motivos reales ¿por qué no fueron consignados con toda naturalidad como razones para motivar el Acuerdo? ¿Los consideraban legítimos o, acaso, deleznables? Si lo primero, no tiene explicación que los ocultaran. Si lo segundo, parece que la Sala - a modo de terapeuta - se propone liberar los pensamientos que el CGPJ reprime (¿por vergonzosos?) y recuperarlos reivindicando su plena normalidad. Pero lo hace sin contar para nada con el CGPJ" ${ }^{, 50}$.

(X) Acaba aquí la saga jurisprudencial, pero sin duda alguna solo de momento: los nombramientos discrecionales en la Carrera Judicial seguirán dando que hablar a la Sala $3^{\text {a }}$ del Tribunal Supremo, a la doctrina, y en muchas ocasiones a la opinión pública. Una materia en la cual, sin dejar de reconocer el margen de discrecionalidad técnica del CGPJ, siempre son bienvenidos los intentos de objetivación. Ello redundará en una mayor seguridad jurídica y también en una mayor sensación de independencia judicial.

\section{BIBLIOGRAFÍA}

ALEGRET BURGUÉS, M.E., "Conclusiones del Grupo de investigación sobre la discriminación positiva", en La discriminación positiva, CGPJ, Manuales de Formación Continuada, núm. 35, Consejo General del Poder Judicial, Madrid, 2006.

IGARTUA SALAVARRÍA, Juan, "Un curioso concepto de «motivación implícita» (Comentarios a la STS 420/2017)", Diario La Ley, núm. 8986, 24/5/2017, Editorial Wolters Kluwer, LA LEY 5222/2017

LOUSADA AROCHENA, J. F., "La maternidad y la conciliación en la ley de igualdad, y en especial su regulación para la Carrera Judicial", en Políticas de género, Cuadernos de Derecho Judicial, tomo V, Consejo General del Poder Judicial, Madrid, 2007.

LOUSADA AROCHENA, J. F. y RON LATAS, R. P., La independencia judicial, Editorial Dykinson, Madrid, 2015.

LOUSADA AROCHENA, J. F. y RON LATAS, R. P., El Consejo General del Poder Judicial, actualmente pendiente de publicación en Punto Didot.

MARTÍNEZ MOYA, J. / SÁEZ RODRÍGUEZ, M. C. (coords.), La protección social de la Carrera Judicial, BOE, Madrid, 2018.

MURILLO DE LA CUEVA, P. L., "El control de la actividad del Consejo General del Poder Judicial en materia de nombramientos y de régimen disciplinario en la jurisprudencia reciente", en Jurisprudencia contencioso-administrativa (2005-2007): análisis crítico, Cuadernos de Derecho Judicial, núm. 125, Consejo General del Poder Judicial, Madrid, 2007.

RON LATAS, R. P. y LOUSADA AROCHENA, J. F., La independencia judicial en la historia constitucional de España (1808-1975), Punto Didot, Madrid, 2017.

\footnotetext{
${ }^{50}$ IGARTUA SALAVARRÍA, Juan, "Un curioso concepto de «motivación implícita» (Comentarios a la STS 420/2017)”, Diario La Ley, núm. 8986, 24/5/2017, Editorial Wolters Kluwer, LA LEY 5222/2017.
} 